\title{
A systematic literature review on the usability of mobile applications for visually impaired users
}

\author{
Muna Alrazgan $^{1}$, Sarah Almoaiqel ${ }^{\text {Corresp., } 1}{ }^{1}$, Noha Al-Rajhi ${ }^{2}$, Alya Al-humaikani ${ }^{1}$, Abeer Alshehri ${ }^{2}$, Bashayr Alnefaie ${ }^{1}$, \\ Raghad AlKhamiss ${ }^{1}$, Shahad Rushdi ${ }^{1}$ \\ ${ }^{1}$ King Saud University, Riyadh, Saudi Arabia \\ 2 Imam Muhammad Ibn Saud University, Riyadh, Saudi Arabia \\ Corresponding Author: Sarah Almoaiqel \\ Email address: salmoaiqel@ksu.edu.sa \\ Interacting with mobile applications can often be challenging for people with visual \\ impairments due to the poor usability of some mobile applications. The goal of this paper \\ is to provide an overview of the developments on usability of mobile applications for \\ people with visual impairments based on recent advances in research and application \\ development. This overview is important to guide decision-making for researchers and \\ provide a synthesis of available evidence and indicate in which direction it is worthwhile to \\ prompt further research. We performed a systematic literature review on the usability of \\ mobile applications for people with visual impairments. A deep analysis following the \\ Preferred Reporting Items for SLRs and Meta-Analyses (PRISMA) guidelines was performed \\ to produce a set of relevant papers in the field. We first identified 932 papers published \\ within the last six years. After screening the papers and employing a snowballing \\ technique, we identified 60 studies that were then classified into seven themes: \\ accessibility, daily activities, assistive devices, navigation, screen division layout, and \\ audio guidance. The studies were then analyzed to answer the proposed research \\ questions in order to illustrate the different trends, themes, and evaluation results of \\ various mobile applications developed in the last six years. Using this overview as a \\ foundation, future directions for research in the field of usability for the visually impaired \\ (UVI) are highlighted.
}




\title{
A Systematic Literature Review on the Usability of Mobile Applications for Visually Impaired Users
}

\author{
Dr. Muna Saleh Alrazgan1, Dr. Sarah Salman Almoaiqel1, Noha Abdullah Al-Rajhi2, Alyah
}

Khaled Al-humaikani1, Abeer Dafer Alshehri2, Bashayr Hamad Alnefaie1, Raghad Abdussalam AlKhamiss1, and Shahad Mohammed Rushdi1

1 Software Engineering Department, King Saud University, Riyadh, Riyadh, Saudi Arabia 2 Computer Science Department, Imam Muhammad Ibn Saud University, Riyadh, Riyadh, Saudi Arabia

Corresponding Author: Dr. Sarah Almoaiqel1 Riyadh, Saudi Arabia

Email address: salmoaiqel@ksu.edu.sa

\section{Abstract}

Interacting with mobile applications can often be challenging for people with visual impairments due to the poor usability of some mobile applications. The goal of this paper is to provide an overview of the developments on usability of mobile applications for people with visual impairments based on recent advances in research and application development. This overview is important to guide decision-making for researchers and provide a synthesis of available evidence and indicate in which direction it is worthwhile to prompt further research. We performed a systematic literature review on the usability of mobile applications for people with visual impairments. A deep analysis following the Preferred Reporting Items for SLRs and MetaAnalyses (PRISMA) guidelines was performed to produce a set of relevant papers in the field. We first identified 932 papers published within the last six years. After screening the papers and employing a snowballing technique, we identified 60 studies that were then classified into seven themes: accessibility, daily activities, assistive devices, navigation, screen division layout, and audio guidance. The studies were then analyzed to answer the proposed research questions in order to illustrate the different trends, themes, and evaluation results of various mobile applications developed in the last six years. Using this overview as a foundation, future directions for research in the field of usability for the visually impaired (UVI) are highlighted. 


\section{Introduction}

The era of mobile devices and applications has begun. With the widespread use of mobile applications, designers and developers need to consider all types of users and develop applications for their different needs. One notable group of users is people with visual impairments. According to the World Health Organization, there are approximately 285 million people with visual impairments worldwide (WHO, 2020). This is a huge number to keep in mind while developing new mobile applications.

People with visual impairments have urged more attention from the tech community to provide them with the assistive technologies they need (Khan \& Khusro, 2021). Small tasks that we do daily, such as picking out outfits or even moving from one room to another, could be challenging for such individuals. Thus, leveraging technology to assist with such tasks can be life changing. Besides, increasing the usability of applications and developing dedicated ones tailored to their needs is essential. The usability of an application refers to its efficiency in terms of the time and effort required to perform a task, its effectiveness in performing said tasks, and its users' satisfaction (Ferreira, 2020). Researchers have been studying this field intensively and proposing different solutions to improve the usability of applications for people with visual impairments.

This paper provides a systematic literature review (SLR) on the usability of mobile applications for people with visual impairments. The study aims to find discussions of usability issues related to people with visual impairments in recent studies and how they were solved using mobile applications. By reviewing published works from the last six years, this SLR aims to update readers on the newest trends, limitations of current research, and future directions in the research field of usability for the visually impaired (UVI).

This SLR can be of great benefit to researchers aiming to become involved in UVI research and could provide the basis for new work to be developed, consequently improving the quality of life for the visually impaired. This review differs from previous review studies (i.e. Khan \& Khusro, 2021) because we classified the studies into themes in order to better evaluate and synthesize the studies and provide clear directions for future work. The following themes were chosen based on the issues addressed in the reviewed papers: "Assistive Devices," "Navigation," "Accessibility," "Daily Activities," "Audio Guidance," and "Gestures." Figure 1 illustrates the percentage of papers classified in each theme.

\section{Figure 1: Percentages of classification themes}

The remainder of this paper is organized as follows: the next section specifies the methodology, following this, the results section illustrates the results of the data collection, the discussion section consists of the research questions with their answers and the limitations and 
74 potential directions for future work, and the final section summarizes this paper's main findings 75 and contribution.

\section{Survey Methodology}

78 This systematic literature review used the Meta-Analyses (PRISMA, 2009) guidelines to 79 produce a set of relevant papers in the field. This SLR was undertaken to address the research 80 questions described below. A deep analysis was performed based on a group of studies; the most 81 relevant studies were documented, and the research questions were addressed.

\section{A. RESEARCH QUESTIONS}

The research questions addressed by this study are presented in Table 1 with descriptions and the motivations behind them.

\section{Table 1: Research questions}

86

87

88

89

90

91

\section{B. SEARCH STRATEGY}

This review analysed and synthesised studies on usability for the visually impaired from a user perspective following a systematic approach. As proposed by Tranfield et al. (Tanfield, Denyer \& Smart, 2003), the study followed a three-stage approach to ensure that the findings were both reliable and valid. These stages were planning the review, conducting the review by analysing papers, and reporting emerging themes and recommendations. These stages will be discussed further in the following section.

\section{PLANNING STAGE}

The planning stage of this review included defining data sources and the search string protocol as well as inclusion and exclusion criteria.

\section{$>$ DATA SOURCES}

We aimed to use two types of data sources: digital libraries and search engines. The search process was manually conducted by searching through databases. The selected databases and digital libraries are as follows:

- ACM Library

- IEEE Xplore

- ScienceDirect

- SpringerLink

- ISI Web of Knowledge

- Scopus. 
106 The selected search engines were as follows:

107 DBLP (Computer Science Bibliography Website)

108 - Google Scholar

109 - Microsoft Academic

110

$111>$ SEARCH STRING

112 The above databases were initially searched using the following keyword protocol:

113 ("Usability" AND ("visual impaired" OR "visually impaired" OR "blind” OR "impairment”)

114 AND "mobile"). However, in order to generate a more powerful search string, the Network

115 Analysis Interface for Literature Studies (NAILS) project was used. NAILS is an automated tool

116 for literature analysis. Its main function is to perform statistical and social network analysis

117 (SNA) on citation data (Knutas et al., 2015). In this study, it was used to check the most

118 important work in the relevant fields as shown in figure 2.

119 NAILS produced a report displaying the most important authors, publications, and keywords 120 and listed the references cited most often in the analysed papers (Knutas et al., 2015). The new

121 search string was generated after using the NAILS project as follows: ("Usability" OR "usability

122 model" OR "usability dimension" OR "Usability evaluation model” OR "Usability evaluation

123 dimension") AND ("mobile" OR "Smartphone") AND ("Visually impaired" OR "Visual

124 impairment" OR "Blind” OR "Low vision" OR "Blindness").

125 Figure 2: NAILS output sample

$126>$ INCLUSION AND EXCLUSION CRITERIA 
127

128

129

130

131

132

133

134

135

136

137

138

139

140

141

142

143

144

145

146

147

148

149

150

151

152

153

154

155

156

157

158

159

160

161

162

To be included in this systematic review, each study had to meet the following screening criteria:

- The study must have been published between 2015 and 2020.

- The study must be relevant to the main topic (Usability of Mobile Applications for Visually Impaired Users).

- The study must be a full-length paper.

- The study must be written in English because any to consider any other languages, the research team will need to use the keywords of this language in this topic and deal with search engines using that language to extract all studies related to our topic to form an SLR with a comprehensive view of the selected languages. Therefore, the research team preferred to focus on studies in English to narrow the scope of this SLR.

A research study was excluded if it did not meet one or more items of the criteria.

\section{CONDUCTING STAGE:}

The conducting stage of the review involved a systematic search based on relevant search terms. This consisted of three substages: exporting citations, importing citations into Mendeley, and importing citations into Rayyan.

\section{$>$ EXPORTING CITATIONS}

First, in exporting the citations and conducting the search through the mentioned databases, a total of 932 studies were found. The numbers are illustrated in Figure 4 below. The highest number of papers was found in Google Scholar, followed by Scopus, ISI Web of Knowledge, ScienceDirect, IEEE Xplore, Microsoft Academic, and DBLP and ACM Library with two studies each. Finally, SpringerLink did not have any studies that met the inclusion criteria.

\section{Figure 3: Number of papers per database}

The chance of encountering duplicate studies was determined to be high. Therefore, importing citations into Mendeley was necessary in order to eliminate the duplicates.

\section{$>$ IMPORTING CITATIONS INTO MENDELEY}

Mendeley is an open-source reference and citation manager. It can highlight paragraphs and sentences, and it can also list automatic references on the end page. Introducing the use of Mendeley is also expected to avoid duplicates in academic writing, especially for systematic literature reviews (Basri \& Patak, 2015). Hence, in the next step, the 932 studies were imported into Mendeley, and each study's title and abstract were screened independently for eligibility. A total of 187 duplicate studies were excluded. 745 total studies remained after the first elimination process.

\section{Figure 4: Search stages}




\section{IMPORTING CITATIONS INTO RAYYAN}

Rayyan QCRI is a free web and mobile application that helps expedite the initial screening of both abstracts and titles through a semi-automated process while incorporating a high level of usability. Its main benefit is to speed up the most tedious part of the systematic literature review process: selecting studies for inclusion in the review (Ouzzani et al., 2016). Therefore, for the last step, another import was done using Rayyan to check for duplications a final time. Using Rayyan, a total of 124 duplicate studies were found, resulting in a total of 621 studies. Using Rayyan, a two-step filtration was conducted to guarantee that the papers have met the inclusion criteria of this SLR. After filtering based on the abstracts, 564 papers did not meet the inclusion criteria. At this stage, 57 studies remained. The second step of filtration eliminated 11 more studies by reading the full papers; two studies were not written in the English language, and nine were inaccessible.

\section{$>$ SNOWBALLING}

Snowballing is an emerging technique used to conduct systematic literature reviews that are considered both efficient and reliable using simple procedures. The procedure for snowballing consisted of three phases in each cycle. The first phase is refining the start set, the second phase is backward snowballing, and the third is forward snowballing. The first step, forming the start set, is basically identifying relevant papers that can have a high potential of satisfying the criteria and research question. Backward snowballing was conducted using the reference list to identify new papers to include. It shall start by going through the reference list and excluding papers that do not fulfill the basic criteria; the rest that fulfil criteria shall be added to the SLR. Forward snowballing refers to identifying new papers based on those papers that cited the paper being examined (Juneja \& Kaur, 2019). Hence, in order to be sure that we concluded all related studies after we got the 46 papers, a snowballing step was essential. Forward and backward snowballing were conducted. Each of the 46 studies was examined by checking their references to take a look at any possible addition of sources and examining all papers that cited this study. The snowballing activity added some 38 studies, but after full reading, it became 33 that matched the inclusion criteria. A total of 79 studies were identified through this process.

\section{$>$ QUALITY ASSESSMENT}

A systematic literature review's quality is determined by the content of the papers included in the review. As a result, it is important to evaluate the papers carefully (Zhou et al., 2015). Many influential scales exist in the software engineering field for evaluating the validity of individual primary studies and grading the overall intensity of the body of proof. Hence, we adapted the comprehensive guidelines specified by Kitchenhand and Charters (Keele, 2007), and the quasigold standard (QGS) (Keele, 2007) was used to establish the quest technique, where a robust search strategy for enhancing the validity and reliability of a SLR's search process is devised using the QGS. By applying this technique, our quality assessment questions were focused and aligned with the research questions mentioned earlier. 
201

202

203

204

205

206

207

208

209

210

211

212

213

214

215

216

217

218

219

220

221

222

223

224

225

226

227

228

229

230

231

232

233

234

235

236

In our last step, we had to verify the papers' eligibility; we conducted a quality check for each of the 79 studies. For quality assessment, we considered whether the paper answered the following questions:

QA1: Is the research aim clearly stated in the research?

QA2: Does the research contain a usability dimension or techniques for mobile applications for people with visual impairments?

QA3: Is there an existing issue with mobile applications for people with visual impairments that the author is trying to solve?

QA4: Is the research focused on mobile application solutions?

After discussing the quality assessment questions and attempting to find an answer in each paper, we agreed to score each study per question. If the study answers a question, it will be given 2 points; if it only partially answers a question, it will be given 1 point; and if there is no answer for a given question in the study, it will have 0 points.

The next step was to calculate the weight of each study. If the total weight was higher or equal to four points, the paper was accepted in the SLR; if not, the paper was discarded since it did not reach the desired quality level. Figure 5 below illustrates the quality assessment process. After applying the quality assessment, 39 papers were rejected since they received less than four points, which resulted in a final tally of 60 papers.

\section{Figure 5: Quality assessment process}

To summarize, this review was conducted according to the Preferred Reporting Items for SLRs and Meta-Analyses (PRISMA) (Liberati et al., 2009). The PRISMA diagram shown in Figure 6 illustrates all systematic literature processes used in this study.

\section{Figure 6: PRISMA flow diagram}

\section{ANALYSING STAGE:}

All researchers involved in this SLR collected the data. The papers were distributed equally between them, and each researcher read each paper completely to determine its topic, extract the paper's limitations and future work, write a quick summary about it, and record this information in an Excel spreadsheet.

\section{RESULTS}

All researchers worked intensively on this systematic literature review. After completing the previously mentioned steps, the papers were divided among all the researchers. Then, each researcher read their assigned papers completely and then classified them into themes according to the topic they covered. The researchers held several meetings to discuss and specify those themes. The themes were identified by the researchers based on the issues addressed in the reviewed papers. In the end, the researchers resulted in seven themes, as shown in Figure 7 
237 below. The references selected for each theme can be found in the Appendix. Afterwards, each 238 researcher was assigned one theme to summarize its studies and report the results. In this 239 section, we review the results.

\section{Figure 7: Results of the SLR}

\section{A. Accessibility}

242 Of a total of 60 studies, 10 focused on issues of accessibility. Accessibility is concerned with 243 whether all users are able to have equivalent user experiences, regardless of abilities. Six studies, 244 (Darvishy, Hutter \& Frei, 2019), (Morris et al., 2016), (Qureshi \& Wong, 2020), (Khan, Khusro 245 \& Alam, 2018), (Paiva et al., 2020), and (Pereda, Murillo \& Paz, 2020), gave suggestions for 246 increasing accessibility, (Darvishy, Hutter \& Frei, 2019), and (Morris et al., 2016), gave some 247 suggestions for making mobile map applications and Twitter accessible to visually impaired 248 users, and (Qureshi \& Wong, 2020) and (Khan, Khusro \& Alam, 2018) focused on user 249 interfaces and provided accessibility suggestions suitable for blind people. (Paiva et al., 2020) 250 and (Pereda, Murillo \& Paz, 2020) proposed a set of heuristics to evaluate the accessibility of

251

252

253

254

255

256

257

258

259

260

261

262

263

264

265

266

267

268

269

270

271

272

273

274 mobile applications. Two studies, (Khowaja et al., 2019) and (Carvalho et al., 2018), focused on evaluating usability and accessibility issues on some mobile applications, comparing them, and identifying the number and types of problems that visually impaired users faced. (Aqle, Khowaja \& Al-Thani, 2020) proposed a new web search interface designed for visually impaired users. One study, (McKay, 2017), focused on accessibility challenges by applying usability tests on a hybrid mobile app with some visually impaired university students.

\section{B. Assistive Devices}

People with visual impairments have an essential need for assistive technology since they face many challenges when performing activities in daily life. Out of the 60 studies reviewed, 13 were related to assistive technology. The studies (Smaradottir, Martinez \& Håland, 2017), (Skulimowski et al.,2019), (Barbosa, Hayes \& Wang, 2016), (Rosner \& Perlman, 2018), (Csapó et al., 2015), (Khan \& Khusro, 2020), (Sonth \& Kallimani, 2017), (Kim et al., 2016), (Vashistha et al., 2015), (Kameswaran et al., 2020), (Shirley et al., 2017), and (Rahman et al., 2017) were related to screen readers (voiceovers). On the other hand, (Bharatia, Ambawane \& Rane, 2019) and (Lewis et al., 2016) were related to proposing an assistant device for the visually impaired. Of the studies related to screening readers, (Sonth \& Kallimani, 2017), (Vashistha et al., 2015), (Khan \& Khusro, 2020) and (Lewis et al.,2016) cited challenges faced by visually impaired users. Barbosa, Hayes \& Wang, 2016), (Kim et al., 2016), and (Rahman et al., 2017) suggested new applications, while (Smaradottir, Martinez \& Håland, 2017), (Rosner \& Perlman, 2018), (Csapó et al., 2015), and (Shirley et al., 2017) evaluated current existing work. The studies (Bharatia, Ambawane \& Rane, 2019) and (Lewis et al., 2016) proposed using wearable devices to improve the quality of life for people with visual impairments. 


\section{C. Daily Activities}

276 In recent years, people with visual impairments have used mobile applications to increase 277 their independence in their daily activities and learning, especially those based on the braille 278 method. We divide the daily activity section into braille-based applications and applications 279 designed to enhance the independence of the visually impaired. Four studies, (Nahar, Sulaiman, 280 \& Jaafar, 2020), (Nahar, Jaafar, \& Sulaiman, 2019), (Araújo et al., 2016), and (Gokhale et al., 281 2017), implemented and evaluated the usability of mobile phone applications that use braille to 282 help visually impaired people in their daily lives. Seven studies, (Vitiello et al., 2018), 283 (Kunaratana-Angkul, Wu, \& Shin-Renn, 2020), (Ghidini et al., 2016), (Madrigal-Cadavid et al., 284 2019), (Marques, Carriço \& Guerreiro, 2015), (Oliveira et al., 2018), and (Rodrigues et al., 285 2015), focused on building applications that enhance the independence and autonomy of people 286 with visual impairments in their daily life activities.

287

288

289

290

291

292

293

294

295

296

297

298

\section{Screen Division Layout}

People with visual impairments encounter various challenges in identifying and locating nonvisual items on touch screen interfaces like phones and tablets. Incidents of accidentally touching a screen element and frequently following an incorrect pattern in attempting to access objects and screen artifacts hinder blind people from performing typical activities on smartphones (Khusro et al., 2019). In this review, 9 out of 60 studies discuss screen division layout: (Khusro et al., 2019), (Khan, \& Khusro, 2019), (Grussenmeyer \& Folmer, 2017), (Palani et al., 2018), and (Leporini \& Palmucci, 2018) discuss touch screen (smartwatch tablets, mobile phones, and tablet) usability among people with visual impairments, while (Cho \& Kim, 2017), (Alnfiai \& Sampalli, 2016), (Niazi et al., 2016), and (Alnfiai \& Sampalli, 2019) concern text entry methods

299

300

301

302

303

304

305

306

307

308

309

310

311

312

313 that increase the usability of apps among visually impaired people. (Khusro et al., 2019) provides a novel contribution to the literature regarding considerations that can be used as guidelines for designing a user-friendly and semantically enriched user interface for blind people. An experiment in (Cho \& Kim, 2017) was conducted comparing the two-button mobile interface usability with the one-finger method and voiceover. (Leporini \& Palmucci, 2018) gathered information on the interaction challenges faced by visually impaired people when answering questions on a mobile touch-screen device, investigated possible solutions to overcome the accessibility and usability challenges.

\section{E. Gestures}

In total, 3 of 60 studies discuss gestures in usability. (Alnfiai \& Sampalli, 2017) compared the performance of BrailleEnter, a gesture based input method to the Swift Braille keyboard, a method that requires finding the location of six buttons representing braille dot, while (Buzzi et al., 2017) and (Smaradottir, Martinez \& Haland, 2017) provide an analysis of gesture performance on touch screens among visually impaired people. 


\section{F. Audio Guidance}

315 People with visual impairment primarily depend on audio guidance forms in their daily lives;

316 accordingly, audio feedback helps guide them in their interaction with mobile applications.

317 Four studies discussed the use of audio guidance in different contexts: one in navigation (Gintner

318 et al., 2017), one in games (Ara' ujo et al., 2017), one in reading (Sabab \& Ashmafee, 2016), and

319 one in videos (Façanha et al., 2016). These studies were developed and evaluated based on

320 usability and accessibility of the audio guidance for people with visual impairments and aimed to

321 utilize mobile applications to increase the enjoyment and independence of such individuals.

322

323

\section{G. Navigation}

324

325

Navigation is a common issue that visually impaired people face. Indoor navigation is widely discussed in the literature. (Nair et al., 2020), (Al-Khalifa \& Al-Razgan, 2016), and (de Borba Campos et al., 2015) discuss how we can develop indoor navigation applications for visually impaired people. Outdoor navigation is also common in the literature, as seen in (Darvishy et al., 2020), (Hossain, Qaiduzzaman \& Rahman, 2020), (Long et al., 2016), (Prerana et al., 2019), and

329

330

331

332

333

334

335

336

337

338

339

340

341

342

343

344

345

346

347

348

349

350

351

352

353 (Bandukda et al., 2020). For example, in (Darvishy et al., 2020), Touch Explorer, an accessible digital map application, was presented to alleviate many of the problems faced by people with visual impairments while using highly visually oriented digital maps. Primarily, it focused on using non-visual output modalities like voice output, everyday sound, and vibration feedback. Issues with navigation applications were also presented in (Maly et al., 2015). (Kameswaran et al., 2020) discussed commonly used technologies in navigation applications for blind people and highlighted the importance of using complementary technologies to convey information through different modalities to enhance the navigation experience. Interactive sonification of images for navigation has also been shown in (Skulimowski et al., 2019).

\section{DISCUSSION}

In this section, the research questions are addressed in detail to clearly achieve the research objective. Also, a detailed overview of each theme will be mentioned below.

\section{Answers to the Research Questions}

This section will answer the research question proposed:

\section{RQ1: What existing UVI issues did authors try to solve with mobile devices?}

Mobile applications can help people with visual impairments in their daily activities, such as navigation and writing. Additionally, mobile devices may be used for entertainment purposes. However, people with visual impairments face various difficulties while performing text entry operations, text selection, and text manipulation on mobile applications (Niazi et al., 2016). Thus, the authors of the studies tried to increase touch screens' usability by producing prototypes or simple systems and doing usability testing to understand the UX of people with visual impairments. 
354

355

356

357

358

359

360

361

362

363

364

365

366

367

368

369

370

371

372

373

374

375

376

377

378

379

380

381

382

383

384

385

386

387

388

389

390

391

\section{RQ2: What is the role of mobile devices in solving those issues?}

Mobile phones are widely used in modern society, especially among users with visual impairments; they are considered the most helpful tool for blind users to communicate with people worldwide (Smaradottir, Martinez \& Håland, 2017). In addition, the technology of touch screen assistive technology enables speech interaction between blind people and mobile devices and permits the use of gestures to interact with a touch user interface. Assistive technology is vital in helping people living with disabilities perform actions or interact with systems (Niazi et al., 2016).

\section{RQ3: What are the publication trends on the usability of mobile applications among the visually impaired?}

As shown in Figure 8 below, research into mobile applications' usability for the visually impaired has increased in the last five years, with a slight dip in 2018. Looking at the most frequent themes, we find that "Assistive Devices" peaked in 2017, while "Navigation" and "Accessibility" increased significantly in 2020. On the other hand, we see that the prevalence of "Daily Activities" stayed stable throughout the research years. The term "Audio Guidance" appeared in 2016 and 2017 and has not appeared in the last three years. "Gestures" also appeared only in 2017. "Screen Layout Division" was present in the literature in the last five years and increased in 2019 but did not appear in 2020.

\section{Figure 8: Publication trends over time}

\section{RQ4: What are the current research limitations and future research directions regarding} usability among the visually impaired?

We divide the answer to this question into two sections: first, we will discuss limitations; then, we will discuss future work for each proposed theme.

\section{A. Limitations}

Studies on the usability of mobile applications for visually impaired users in the literature have various limitations, and most of them were common among the studies. These limitations were divided into two groups. The first group concerns proposed applications; for example, (Rahman et al., 2017), (Oliveira et al., 2018), and (Madrigal-Cadavid et al., 2019) faced issues regarding camera applications in mobile devices due to the considerable effort needed for its usage and being heavily dependent on the availability of the internet. The other group of studies, (Rodrigues et al., 2015), (Leporini \& Palmucci, 2018), (Alnfiai \& Sampalli, 2016), and (Ara ujo et al., 2017), have shown limitations in visually impaired users' inability to comprehend a graphical user interface. (Alnfiai \& Sampalli, 2017) and (Alnfiai \& Sampalli, 2019) evaluated new braille input methods and found that the traditional braille keyboard, where knowing the exact position of letters QWERTY is required, is limited in terms of usability compared to the new input methods. Most studies faced difficulties regarding the sample size and the fact that many of the participants were not actually blind or visually impaired but only blindfolded. This 
392 likely led to less accurate results, as blind or visually impaired people can provide more useful

393

394

395

396

397

398

399

400

401

402

403

404

405

406

407

408

409

410

411

412

413

414

415

416

417

418

419

420

421

422

423

424

425

426

427

428

429

feedback as they experience different issues on a daily basis and are more ideal for this type of study. So, the need for a good sample of participants who actually have this disability is clear to allow for better evaluation results and more feedback and recommendations for future research.

\section{B. Future Work}

A commonly discussed future work in the chosen literature is to increase the sample sizes of people with visual impairment and focus on various ages and geographical areas to generalize the studies. Table 2 summarizes suggestions for future work according to each theme. Those future directions could inspire new research in the field.

\section{Table 2: Theme-based future work}

RQ5: What is the focus of research on usability for visually impaired people, and what are the research outcomes in the studies reviewed?

There are a total of 60 outcomes in this research. Of these, 40 involve suggestions to improve usability of mobile applications; four of them address problems that are faced by visually impaired people that reduce usability. Additionally, 16 of the outcomes are assessments of the usability of the prototype or model. Two of the results are recommendations to improve usability. Finally, the last two outcomes are hardware solutions that may help the visually impaired perform their daily activities. Figure 9 illustrates these numbers.

\section{Figure 9: Outcomes of studies}

\section{Overview of the reviewed studies}

In the following subsections, we summarize all the selected studies based on the classified theme: accessibility, assistive devices, daily activities, screen division layout, gestures, audio guidance, and navigation. The essence of the studies will be determined, and their significance in the field will be explored.

\section{A. Accessibility}

For designers dealing with mobile applications, it is critical to determine and fix accessibility issues in the application before it is delivered to the users (Khowaja et al., 2019). Accessibility refers to giving the users the same user experience regardless of ability. In (Khowaja et al., 2019) and (Carvalho et al., 2018), the researchers focused on comparing the levels of accessibility and usability in different applications. They had a group of visually impaired users and a group of sighted users test out the applications to compare the number and type of problems they faced and determine which applications contained the most violations. Because people with visual impairments cannot be ignored in the development of mobile applications, many researchers have sought solutions for guaranteeing accessibility. For example, in (Qureshi \& Wong, 2020), the study contributed to producing a new, effective design for mobile applications based on the suggestions of people with visual impairments and with the help of two expert mobile application developers. In (Khan, Khusro \& Alam, 2018), an adaptive user interface model for 
430 visually impaired people was proposed and evaluated in an empirical study with 63 visually 431 impaired people. In (Aqle, Khowaja \& Al-Thani,2020), the researchers proposed a new web 432 search interface for users with visual impairments that is based on discovering concepts through 433 formal concept analysis (FCA). Users interact with the interface to collect concepts, which are

434

435

436

437

438

439

440

441

442

443

444

445

446

447

448

449

450

451

452

453

454

455

456

457

458

459

460

461

462

463

464

465

466

467

468

469

then used as keywords to narrow the search results and target the web pages containing the desired information with minimal effort and time. The usability of the proposed search interface (InteractSE) was evaluated by experts in the field of HCI and accessibility, with a set of heuristics by Nielsen and a set of WCAG 2.0 guidelines.

In (Darvishy, Hutter \& Frei, 2019), the researchers proposed a solution for making mobile map applications accessible for people with blindness or visual impairment. They suggested replacing forests in the map with green color and birds' sound, replacing water with blue color and water sounds, replacing streets with grey color and vibration, and replacing buildings with yellow color and pronouncing the name of the building. The prototype showed that it was possible to explore a simple map through vibrations, sounds, and speech.

In (Morris et al., 2016), the researchers utilized a multi-faceted technique to investigate how and why visually impaired individuals use Twitter and the difficulties they face in doing so. They noted that Twitter had become more image-heavy over time and that picture-based tweets are largely inaccessible to people with visual impairments. The researchers then made several suggestions for how Twitter could be amended to continue to be usable for people with visual impairments.

The researchers in (Paiva et al., 2020) focused on how to evaluate proposed methods for ensuring the accessibility and usability of mobile applications. Their checklist, AccMobileCheck, contains 47 items that correspond to issues related to comprehension (C), operation (O), perception (P), and adaptation (A) in mobile interface interaction. To validate Acc-MobileCheck, it was reviewed by five experts and three developers and determined to be effective. In (Pereda, Murillo \& Paz, 2020), the authors also suggest a set of heuristics to evaluate the accessibility of mobile e-commerce applications for visually impaired people. Finally, (McKay, 2017) conducted an accessibility test for hybrid mobile apps and found that students with blindness faced many barriers to access based on how they used hybrid mobile applications. While hybrid apps can allow for increased time for marketing, this comes at the cost of app accessibility for people with disabilities.

\section{B. Assistive Devices}

A significant number of people with visual impairments use state-of-the-art software to perform tasks in their daily lives. These technologies are made up of electronic devices equipped with sensors and processors that can make intelligent decisions.

One of the most important and challenging tasks in developing such technologies is to create a user interface that is appropriate for the sensorimotor capabilities of users with blindness (Csapó et al., 2015). Several new hardware tools have proposed to improve the quality of life for people with visual impairments. Three tools were presented in this SLR: a smart stick that can

Peer) Comput. Sci. reviewing PDF | (CS-2021:07:63198:2:0:CHECK 9 Oct 2021) 
470 notify the user of any obstacle, helping them to perform tasks easily and efficiently (Bharatia, 471 Ambawane \& Rane, 2019), and an eye that can allow users to detect colors (medical evaluation 472 is still required) (Lewis et al.,2016).

473 The purpose of the study in (Shirley et al., 2017) was to understand how people with 474 blindness use smartphone applications as assistive technology and how they perceive them in 475 terms of accessibility and usability. An online survey with 259 participants was conducted, and

476

477

478

479

480

481

482

483

484

485

486

487

488

489

490

491

492

493

494

495

496

497

498

499

500

501

502

503

504

505

506

507

508

509 most of the participants rated the applications as useful and accessible and were satisfied with them.

The researchers in (Rahman et al., 2017) designed and implemented EmoAssist, which is a smartphone application that assists with natural dyadic conversations and aims to promote user satisfaction by providing options for accessing non-verbal communication that predicts behavioural expressions and contains interactive dimensions to provide valid feedback. The usability of this application was evaluated in a study with ten people with blindness where several tools were applied in the application. The study participants found that the usability of EmoAssist was good, and it was an effective assistive solution.

\section{Daily Activities}

This theme contains two main categories: braille-based application studies and applications to enhance the independence of VIU. Both are summarized below.

1- Braille-based applications

Braille is still the most popular method for assisting people with visual impairments in reading and studying, and most educational mobile phone applications are limited to sighted people. Recently, however, some researchers have developed assistive education applications for students with visual impairments, especially those in developing countries. For example, in India, the number of children with visual impairments is around 15 million, and only $5 \%$ receive an education (Gokhale et al., 2017). Three of the braille studies focused on education: (Nahar, Sulaiman, \& Jaafar, 2020), (Nahar, Jaafar, \& Sulaiman, 2019), and (Araújo et al., 2016). These studies all used smartphone touchscreens and action gestures to gain input from the student, and then output was provided in the form of audio feedback. In (Nahar, Sulaiman, \& Jaafar, 2020), vibrational feedback was added to guide the users. The participants in (Nahar, Sulaiman, \& Jaafar, 2020), (Nahar, Jaafar, \& Sulaiman, 2019), and (Araújo et al., 2016) included students with blindness of visual impairment and their teachers. The authors in (Nahar, Sulaiman, \& Jaafar, 2020) and (Nahar, Jaafar, \& Sulaiman, 2019) evaluated the usability of their applications following the same criteria (efficiency, learnability, memorability, errors, and satisfaction). The results showed that in (Nahar, Sulaiman, \& Jaafar, 2020), (Nahar, Jaafar, \& Sulaiman, 2019), and (Araújo et al., 2016), the applications met the required usability criteria. The authors in (Gokhale et al., 2017) presented a braille-based solution to help people with visual impairments call and save contacts. A braille keypad on the smartphone touchscreen was used to gain input from the user, which was then converted into haptic and auditory feedback to let the user know what action was taken. The usability of this application was considered before it was designed. The 
510 participants' responses were positive because this kind of user-centric design simplifies

511 navigation and learning processes.

512 2- Applications to Enhance the Independence of People with Visual Impairments

513 The authors in the studies explored in this section focused on building applications that

514 enhance independence and autonomy in daily life activities for users with visual impairments.

515 In (Vitiello et al., 2018), the authors presented their mobile application, an assistive solution

516 for visually impaired users called "Crania", which uses machine learning techniques to help

517 users with visual impairments get dressed by recognizing the colour and texture of their clothing

518 and suggesting suitable combinations. The system provides feedback through voice synthesis.

519 The participants in the study were adults and elderly people, some of whom were completely

520 blind and the rest of whom had partial sight. After testing for usability, all the participants with

521 blindness agreed that using the application was better than their original method, and half of the

522 participants with partial sight said the same thing. At the end of the study, the application was

523 determined to be accessible and easy to use.

524 In (Kunaratana-Angkul, Wu, \& Shin-Renn, 2020), an application which allows elderly

525 people to measure low vision status at home through their smartphones instead of visiting

526 hospitals was tested, and most of the participants considered it to be untrustworthy because the

527 medical information was insufficient. Even when participants were able to learn how to use the

528 application, most of them were still confused while using it and needed further instruction.

529 In (Ghidini et al., 2016), the authors studied the habits of people with visual impairments

530 when using their smartphones in order to develop an electronic calendar with different

531 interaction formats, such as voice commands, touch, and vibration interaction. The authors

532 presented the lessons learned and categorized them based on usability heuristics such as

533 feedback, design, user freedom and control, and recognition instead of remembering.

534 In (Madrigal-Cadavid et al., 2019), the authors developed a drug information application for

535 people with visual impairments to help them access the labels of medications. The application

536 was developed based on a user-centered design process. By conducting a usability test, the

537 authors recognized some usability issues for people with visual impairments, such as difficulty in

538 locating the bar code. Given this, a new version will include a search function that is based on

539 pictures. The application is searched by capturing the bar code or text or giving voice commands

540 that allow the user to access medication information. The participants were people with visual

541 impairments, and most of them required assistance using medications before using the

542 application. This application will enhance independence for people with visual impairments in

543 terms of using medications.

544 In (Marques, Carriço \& Guerreiro, 2015), an authentication method is proposed for users

545 with visual impairments that allows them to protect their passwords. It is not secure when blind

546 or visually impaired users spell out their passwords or enter the numbers in front of others, and

547 the proposed solution allows the users to enter their password with one hand by tapping the

548 screen. The blind participants in this study demonstrated that this authentication method is usable

549 and supports their security needs. 
550

551

552

553

554

555

556

557

558

559

560

561

562

563

564

565

566

567

568

569

570

571

572

573

574

575

576

577

578

579

580

581

582

583

584

585

586

587

588

589

In (Oliveira et al., 2018), the author noted that people with visual impairments face challenges in reading, thus he proposed an application called LeR'otulos. This application was developed and evaluated for the Android operating system and recognizes text from photos taken by the mobile camera and converts them into an audio description. The prototype was designed to follow the guidelines and recommendations of usability and accessibility. The requirements of the application are defined based on the following usability goals: the steps are easy for the user to remember; the application is efficient, safe, useful, and accessible; and user satisfaction is achieved.

Interacting with talkback audio devices is still difficult for people with blindness, and it is unclear how much benefit they provide to people with visual impairments in their daily activities. The author in (Rodrigues et al., 2015) investigates the smartphone adoption process of blind users by conducting experiments, observations, and weekly interviews. An eight-week study was conducted with five visually impaired participants using Samsung and an enabled talkback 2 screen reader. Focusing on understanding the experiences of people with visual impairments when using touchscreen smartphones revealed accessibility and usability issues. The results showed that the participants have difficulties using smartphones because they fear that they cannot use them properly, and that impacts their ability to communicate with family. However, they appreciate the benefits of using smartphones in their daily activities, and they have the ability to use them.

\section{Screen Division Layout}

People with visual impairments encounter various challenges identifying and locating nonvisual items on touch screen interfaces, such as phones and tablets. Various specifications for developing a user interface for people with visual impairments must be met, such as having touch screen division to enable people with blindness to easily and comfortably locate objects and items that are non-visual on the screen (Khusro et al., 2019). Article (Khusro et al., 2019) highlighted the importance of aspects of the usability analysis, such as screen partitioning, to meet specific usability requirements, including orientation, consistency, operation, time consumption, and navigation complexity when users want to locate objects on their touchscreen. The authors of (Khan, \& Khusro, 2019) describe the improvements that people with blindness have experienced in using the smartphone while performing their daily tasks. This information was determined through an empirical study with 41 people with blindness who explained their user and interaction experiences operating a smartphone.

The authors in (Palani et al., 2018) provide design guidelines governing the accurate display of haptically perceived graphical materials. Determining the usability parameters and the various cognitive abilities required for optimum and accurate use of device interfaces is crucial. Also the authors of (Grussenmeyer \& Folmer, 2017) highlight the importance of usability and accessibility of smartphones and touch screens for people with visual impairments. The primary focus in (Leporini \& Palmucci, 2018) is on interactive tasks used to finish exercises and to answer questionnaires or quizzes. These tools are used for evaluation tests or in games. When

Peer] Comput. Sci. reviewing PDF | (CS-2021:07:63198:2:0:CHECK 9 Oct 2021) 
590 using gestures and screen readers to interact on a mobile device, difficulties may arise (Leporini 591 \& Palmucci, 2018), The study has various objectives, including gathering information on the 592 difficulties encountered by people with blindness during interactions with mobile touch screen 593 devices to answer questions and investigating practicable solutions to solve the detected

594

595

596

597

598

599

600

601

602

603

604

605

606

607

608

609

610

611

612

613

614

615

616

617

618

619

620

621

622

623

624

625

626

627

628

629 accessibility and usability issues. A mobile app with an educational game was used to apply the proposed approach. Moreover, in (Alnfiai \& Sampalli, 2016) and (Niazi et al., 2016), an analysis of the single-tap braille keyboard created to help people with no or low vision while using touch screen smartphones was conducted. The technology used in (Alnfiai \& Sampalli, 2016) was the talkback service, which provides the user with verbal feedback from the application, allowing users with blindness to key in characters according to braille patterns. To evaluate single tap braille, it was compared to the commonly used QWERTY keyboard. In (Niazi et al., 2016), it was found that participants adapted quickly to single-tap Braille and were able to type on the touch screen within 15 to 20 minutes of being introduced to this system. The main advantage of single tap braille is that it allows users with blindness to enter letters based on braille coding, which they are already familiar with. The average error rate is lower using single-tap Braille than it is on the QWERTY keyboard. The authors of (Niazi et al., 2016) found that minimal typing errors were made using the proposed keypad, which made it an easier option for people with blindness (Niazi et al., 2016). In (Cho \& Kim, 2017), the authors describe new text entry methods for the braille system including a left touch and a double touch scheme that form a twobutton interface for braille input so that people with visual impairments are able to type textual characters without having to move their fingers to locate the target buttons.

\section{E. Gestures}

One of the main problems affecting the visually impaired is limited mobility for some gestures. We need to know what gestures are usable by people with visual impairments. Moreover, the technology of assistive touchscreen-enabled speech interaction between blind people and mobile devices permits the use of gestures to interact with a touch user interface. Assistive technology is vital in helping people living with disabilities to perform actions or interact with systems. (Smaradottir, Martinez \& Haland, 2017) analyses a voiceover screen reader used in Apple Inc.'s products. An assessment of this assistive technology was conducted with six visually impaired test participants. The main objectives were to pinpoint the difficulties related to the performance of gestures applicable in screen interactions and to analyze the system's response to the gestures. In this study, a user evaluation was completed in three phases. The first phase entailed training users regarding different hand gestures, the second phase was carried out in a usability laboratory where participants were familiarized with technological devices, and the third phase required participants to solve different tasks. In (Knutas et al., 2015), the vital feature of the system is that it enables the user to interactively select a 3D scene region for sonification by merely touching the phone screen. It uses three different modes to increase usability. (Alnfiai \& Sampalli, 2017) explained a study done to compare the use of two data input methods to evaluate their efficiency with completely blind participants who had prior 
630 knowledge of braille. The comparison was made between the braille enter input method that uses

631

632

633

634

635

636

637

638

639

640

641

642

643

644

645

646

647

648

649

650

651

652

653

654

655

656

657

658

659

660

661

662

663

664

665

666

667

668

669

gestures and the swift braille keyboard, which necessitates finding six buttons representing braille dots. Blind people typically prefer rounded shapes to angular ones when performing complex gestures, as they experience difficulties performing straight gestures with right angles. Participants highlighted that they experienced difficulties particularly with gestures that have steep or right angles. In (Buzzi et al., 2017), 36 visually impaired participants were selected and split into two groups of low-vision and blind people. They examined their touch-based gesture preferences in terms of the number of strokes, multitouch, and shape angles. For this reason, a wireless system was created to record sample gestures from various participants simultaneously while monitoring the capture process.

\section{F. Audio Guidance}

People with visual impairment typically cannot travel without guidance due to the inaccuracy of current navigation systems in describing roads and especially sidewalks. Thus, the author of (Gintner et al., 2017) aims to design a system to guide people with visual impairments based on geographical features and addresses them through a user interface that converts text to audio using a built-in voiceover engine (Apple iOS). The system was evaluated positively in terms of accessibility and usability as tested in a qualitative study involving six participants with visual impairment.

Based on challenges faced by visually impaired game developers, (Ará ujo et al., 2017) provides guidance for developers to provide accessibility in digital games by using audio guidance for players with visual impairments. The interactions of the player can be conveyed through audio and other basic mobile device components with criteria focused on the game level and speed adjustments, high contrast interfaces, accessible menus, and friendly design. Without braille, people with visual impairments cannot read, but braille is expensive and takes effort, and so it is important to propose technology to facilitate reading for them. In (Sabab \& Ashmafee, 2016), the author proposed developing a mobile application called "Blind Reader" that reads an audio document and allows the user to interact with the application to gain knowledge. This application was evaluated with 11 participants, and the participants were satisfied with the application. Videos are an important form of digital media, and unfortunately people with visual impairment cannot access these videos. Therefore, (Façanha et al., 2016) aims to discover sound synthesis techniques to maximize and accelerate the production of audio descriptions with lowcost phonetic description tools. This tool has been evaluated based on usability with eight people and resulted in a high acceptance rate among users.

\section{G. Navigation}

1- Indoor Navigation

Visually impaired people face critical problems when navigating from one place to another. Whether indoors or outdoors, they tend to stay in one place to avoid the risk of injury or seek the help of a sighted person before moving (Al-Khalifa \& Al-Razgan, 2016). Thus, aid in navigation

Peer) Comput. Sci. reviewing PDF | (CS-2021:07:63198:2:0:CHECK 9 Oct 2021) 
670 is essential for those individuals. In (Nair et al., 2020), Nair developed an application called 671 ASSIST, which leverages 19 Bluetooth low energy (BLE) beacons and augmented reality (AR) 672 to help visually impaired people move around cluttered indoor places (e.g., subways) and 673 provide the needed safe guidance, just like having a sighted person lead the way. In the subway 674 example, the beacons will be distributed across the halls of the subway and the application will 675 detect them. Sensors and cameras attached to the individual will detect their exact location and 676 send the data to the application. The application will then give a sequence of audio feedback 677 explaining how to move around the place to reach a specific point (e.g., "in 50 feet turn right", 678 "now turn left", "you will reach the destination in 20 steps"). The application also has an 679 interface for sighted and low-vision users that shows the next steps and instructions. A usability 680 study was conducted to test different aspects of the proposed solution. The majority of the 681 participants agreed that they could easily reach a specified location using the application without

682

683

684

685

686

687

688

689

690

691

692

693

694

695

696

697

698

699

700

701

702

703

704

705

706

707

708

709

the help of a sighted person. A survey conducted to give suggestions from the participants for future improvements showed that most participants wanted to attach their phones to their bodies and for the application to consider the different walking speeds of users. They were happy with the audio and vibration feedback that was given before each step or turn they had to take.

In (Al-Khalifa \& Al-Razgan, 2016), the main purpose of the study was to provide an Arabiclanguage application for guidance inside buildings using Google Glass and an associated mobile application. First, the building plan must be set by a sighted person who configures the different locations needed. Ebsar will ask the map builder to mark each interesting location with a QR code and generate a room number, and the required steps and turns are tracked using the mobile device's built-in compass and accelerometer features. All of these are recorded in the application for the use of a visually impaired individual, and at the end, a full map is generated for the building. After setting the building map, a user can navigate inside the building with the help of Ebsar, paired with Google Glass, for input and output purposes. The efficiency, effectiveness, and levels of user satisfaction with this solution were evaluated. The results showed that the errors made were few, indicating that Ebsar is highly effective. The time consumed in performing tasks ranged from medium to low depending on the task; this can be improved later. Interviews with participants indicated the application's ease of use. (de Borba Campos et al., 2015) shows an application simulating a museum map for people with visual impairments. It discusses whether mental maps and interactive games can be used by people with visual impairments to recognize the space around them. After multiple usability evaluation sessions, the mobile application showed high efficiency among participants in understanding the museum's map without repeating the visitation. The authors make a few suggestions based on feedback from the participants regarding enhancing usability, including using audio cues, adding contextual help to realise the activities carried around in a space, and focusing on audio feedback instead of graphics.

2- Outdoor Navigation

Outdoor navigation is also commonly discussed in the literature. In (Darvishy et al., 2020), Touch Explorer was presented to alleviate many of the problems faced by visually impaired

Peer] Comput. Sci. reviewing PDF | (CS-2021:07:63198:2:0:CHECK 9 Oct 2021) 
710 people in navigation by developing a non-visual mobile digital map. The application relies on

711 three major methods of communication with the user: voice output, vibration feedback, and

712 everyday sounds. The prototype was developed using simple abstract visuals and mostly relies

713 on voice for explanation of the content. Usability tests show the great impact the prototype had

714 on the understanding of the elements of the map. Few suggestions were given by the participants

715 to increase usability, including GPS localization to locate the user on the map, a scale element

716 for measuring the distance between two map elements, and an address search function.

717 In (Hossain, Qaiduzzaman \& Rahman, 2020), a navigation application called Sightless Helper

718 was developed to provide a safe navigation method for people with visual impairments. It relies

719 on footstep counting and GPS location to provide the needed guidance. It can also ensure safe

720 navigation by detect objects and unsafe areas and can detect unusual shaking of the user and alert

721 an emergency contact about the problem. The user interaction categories are voice recognition,

722 touchpad, buttons, and shaking sensors. After multiple evaluations, the application was found to

723 be useful in different scenarios and was considered usable by people with visual impairments.

724 The authors in (Long et al., 2016) propose an application that uses both updates from users and

725 information about the real world to help visually impaired people navigate outdoor settings.

726 After interviews with participants, some design goals were set, including the ability to tag an

727 obstacle on the map, check the weather, and provide an emergency service. The application was

728 evaluated and was found to be of great benefit; users made few errors and found it easy to use. In

729 (Prerana et al., 2019), a mobile application called STAVI was presented to help visually impaired

730 people navigate from a source to a destination safely and avoid issues of re-routing. The

731 application depends on voice commands and voice output. The application also has additional

732 features, such as calling, messages, and emergency help. The authors in (Bandukda et al., 2020)

733 helped people with visual impairments explore parks and natural spaces using a framework

734 called PLACES. Different interviews and surveys were conducted to identify the issues visually

735 impaired people face when they want to do any leisure activity. These were considered in the

736 development of the framework, and some design directions were presented, such as the use of

737 audio to share an experience.

738 3- General Issues

739 The authors in (Maly et al., 2015) discuss implementing an evaluation model to assess the

740 usability of a navigation application and to understand the issues of communication with mobile

741 applications that people with visual impairments face. The evaluation tool was designed using a

742 client-server architecture and was applied to test the usability of an existing navigation

743 application. The tool was successful in capturing many issues related to navigation and user

744 behavior, especially the issue of different timing between the actual voice instruction and the

745 position of the user. The authors in (Kameswaran et al., 2020) conducted a study to find out

746 which navigation technologies blind people can use and to understand the complementarity

747 between navigation technologies and their impact on navigation for visually impaired users. The

748 results of the study show that visually impaired people use both assistive technologies and those

749 designed for non-visually impaired users. Improving voice agents in navigation applications was 
750

751

752

753

754

755

756

757

758

759

760

761

762

763

764

765

766

767

768

769

770

771

772

773

774

775

776

777

778

779

780

781

782

783

784

785

discussed as a design implication for the visually impaired. In (Skulimowski et al.,2019), the authors show how interactive sonification can be used in simple travel aids for the blind. It uses depth images and a histogram called U-depth, which is simple auditory representations for blind users. The vital feature of this system is that it enables the user to interactively select a 3D scene region for sonification by touching the phone screen. This sonic representation of 3D scenes allows users to identify the environment's general appearance and determine objects' distance. The prototype structure was tested by three blind individuals who successfully performed the indoor task. Among the test scenes used included walking along an empty corridor, walking along a corridor with obstacles, and locating an opening between obstacles. However, the results showed that it took a long time for the testers to locate narrow spaces between obstacles.

RQ6: What evaluation methods were used in the studies on usability for visually impaired people that were reviewed?

The most prevalent methods to evaluate the usability of applications were surveys and interviews. These were used to determine the usability of the proposed solutions and obtain feedback and suggestions regarding additional features needed to enhance the usability from the participants' points of view. Focus groups were also used extensively in the literature. Many of the participants selected were blindfolded and were not actually blind or visually impaired. Moreover, the samples selected for the evaluation methods mentioned above considered the age factor depending on the study's needs.

\section{Limitation and future work}

The limitations of this paper are mainly related to the methodology followed. Focusing on just eight online databases and restricting the search with the previously specified keywords and string may have limited the number of search results. Additionally, a large number of papers were excluded because they were written in other languages. Access limitations were also faced due to some libraries asking for fees to access the papers. Therefore, for future works, a study to expand on the SLR results and reveal the current usability models of mobile applications for the visually impaired to verify the SLR results is needed so that this work contributes positively to assessing difficulties and expanding the field of usability of mobile applications for users with visual impairments.

\section{Conclusions}

In recent years, the number of applications focused on people with visual impairments has grown, which has led to positive enhancements in those people's lives, especially if they do not have people around to assist them. In this paper, the research papers focusing on Usability for Visually Impaired Users were analyzed and classified into seven themes: accessibility, daily 
786

787

788

789

790

791

792

793

794

795

796

797

798

799

800

801

802

803

804

805

806

807

808

809

810

811

\section{Acknowledgment}

813 This research project was supported by a grant from the Research Center of the Female Scientific 814

activities, assistive devices, gestures, navigation, screen division layout, and audio guidance. We found that various research studies focus on accessibility of mobile applications to ensure that the same user experience is available to all users, regardless of their abilities. We found many studies that focus on how the design of the applications can assist in performing daily life activities like braille-based application studies and applications to enhance the independence of VI users. We also found papers that discuss the role of assistive devices like screen readers and wearable devices in solving challenges faced by VI users and thus improving their quality of life. We also found that some research papers discuss limited mobility of some gestures for VI users and investigated ways in which we can know what gestures are usable by people with visual impairments. We found many research papers that focus on improving navigation for VI users by incorporating different output modalities like sound and vibration. We also found various studies focusing on screen division layout. By dividing the screen and focusing on visual impairmentrelated issues while developing user interfaces, visually impaired users can easily locate the objects and items on the screens. Finally, we found papers that focus on audio guidance to improve usability. The proposed applications use voice-over and speech interactions to guide visually impaired users in performing different activities through their mobiles. Most of the researchers focused on usability in different applications and evaluated the usability issues of these applications with visually impaired participants. Some of the studies included sighted participants to compare the number and type of problems they faced. The usability evaluation was generally based on the following criteria: accessibility, efficiency, learnability, memorability, errors, safety, and satisfaction. Many of the studied applications show a good indication of these applications' usability and follow the participants' comments to ensure additional enhancements in usability. This paper aims to provide an overview of the developments on usability of mobile applications for people with visual impairments and use this overview to highlight potential future directions.

and Medical Colleges, Deanship of Scientific Research, King Saud University.

Peer] Comput. Sci. reviewing PDF | (CS-2021:07:63198:2:0:CHECK 9 Oct 2021) 


\section{References}

816 Al-Khalifa. S and Al-Razgan. M. 2016. "Ebsar: Indoor guidance for the visually impaired," in 817 Computers \& Electrical Engineering, vol. 54, pp. 26-39.

818

819

Alnfiai. M, \& Sampali. S. 2017. "An evaluation of the brailleenter keyboard: An input method

820 based on braille patterns for touchscreen devices," in 2017 International Conference on

821 Computer and Applications (ICCA) (pp. 107-119). IEEE.

822

823

Alnfiai. M, \& Sampalli. S. 2016. "An evaluation of SingleTapBraille keyboard: a text entry

824 method that utilizes braille patterns on touchscreen devices," in Proceedings of the 18th

825 International ACM SIGACCESS Conference on Computers and Accessibility (pp. 161-169).

826

827

Alnfiai. M, \& Sampalli. S. 2019. "BraillePassword: accessible web authentication technique on

828 touchscreen devices," in Journal of Ambient Intelligence and Humanized Computing, 10(6),

829 2375-2391.

830

831

Aqle. A, Khowaja. K, and Al-Thani. D. 2020. "Preliminary Evaluation of Interactive Search

832 Engine Interface for Visually Impaired Users,” in IEEE Access, vol. 8, pp. 45061-45070, doi:

833 10.1109/ACCESS.2020.2977593.

834

835

Ara ujo. M, Fac anha. A, Darin. T, anchez. J, Andrade. R and Viana. W. 2017. "Mobile Audio 836 Games Accessibility Evaluation for Users Who Are Blind," in 2017 International Conference on 837 Universal Access in Human-Computer Interaction, pp. 242-259. Springer, Cham.

838

839

Araújo. M, et al. 2016. "Design and usability of a braille-based mobile audiogame

840 environment," in Proceedings of the 31st Annual ACM Symposium on Applied Computing -

841 SAC '16, Pisa, Italy, pp. 232-238, doi: 10.1145/2851613.2851701.

842

843 Bandukda. M, Holloway. C, Singh. A, and Berthouze. N. 2020. "PLACES: A Framework for

844 Supporting Blind and Partially Sighted People in Outdoor Leisure Activities," in the 22nd

845 International ACM SIGACCESS Conference on Computers and Accessibility, pp. 1-13.

846

847 Barbosa. N, Hayes. J, and Wang. Y. 2016. "UniPass: design and evaluation of a smart device848 based password manager for visually impaired users," in Proceedings of the 2016 ACM 849 International Joint Conference on Pervasive and Ubiquitous Computing (UbiComp '16). 850 Association for Computing Machinery, New York, NY, USA, 49-60.

851 Doi:https://doi.org/10.1145/2971648.2971722

852 
853 Basri. M and Patak. A. 2015. "Exploring Indonesian students' perception on Mendeley

854 Reference Management Software in academic writing," in 2015 2nd International Conference on

855 Information Technology, Computer, and Electrical Engineering (ICITACEE), pp. 8-13, doi:

856 10.1109/ICITACEE.2015.7437761.

857

858

Bastien. J. 2010. "Usability testing: a review of some methodological and technical aspects of

859 the method," in International journal of medical informatics, vol. 79, no. 4, pp. e18-e23.

860

861

Bharatia. D, Ambawane. P and Rane. P. 2019. "Smart Electronic Stick for Visually Impaired

862 using Android Application and Google's Cloud Vision," in 2019 Global Conference for

863 Advancement in Technology (GCAT), BANGALURU, India, pp. 1-6, doi:

864 10.1109/GCAT47503.2019.8978303.

865

866

Brady. E, Morris .M, Zhong. Y, White. S, and Bigham.J. 2013. "Visual challenges in the

867 everyday lives of blind people," in Proceedings of the SIGCHI conference on human factors in

868 computing systems, pp. 2117-2126.

869

870

Buzzi. M, Buzzi. M, Leporini. B, \& Trujillo. A. 2017. “Analyzing visually impaired people's

871 touch gestures on smartphones," in Multimedia Tools and Applications, 76(4), 5141-5169.

872

873 Carvalho. $M$ et al. 2018. "Accessibility and Usability Problems Encountered on Websites and

874 Applications in Mobile Devices by Blind and Normal-Vision Users," in pp. 2022-2029, doi:

$87510.1145 / 3167132.3167349$.

876

877 Cho. H and Kim. J. 2017. "Two-button Mobile Interface: Touchscreen Based Text-Entry for 878 Visually-Impaired Users" in ACHI.

879

880 Csapó. Á, Wersényi. G, Nagy. H, et al. 2015. "A survey of assistive technologies and

881 applications for blind users on mobile platforms: a review and foundation for research," in J

882 Multimodal User Interfaces 9, 275-286. https://doi.org/10.1007/s12193-015-0182-7

883

884 Darvishy. A, Hutter. H, and Frei.J. 2019. "Making mobile map applications accessible for 885 visually impaired people," in International Conference on Human Interaction and Emerging 886 Technologies, pp. 396-400.

887

888 Darvishy. A, Hutter. H, Grossenbacher. M, and Merz. D. 2020. "Touch Explorer: Exploring 889 Digital Maps for Visually Impaired People," in International Conference on Computers Helping 890 People with Special Needs, pp. 427-434.

891 
892 de Borba Campos. M, Sánchez. J, Damasio. J, and Inácio. T. 2015. "Usability evaluation of a 893 mobile navigation application for blind users," in International Conference on Universal Access 894 in Human-Computer Interaction, pp. 117-128.

895

896

897

898

899

900

901

902

903

904

905

906

907

908

909

910

911

912

913

914

915

916

917

918

919

920

921

922

923

924

925

926

927

928

929

Façanha. A, de Oliveira. A, Lima. M and Viana. W. 2016. "Audio Description of Videos for People with Visual Disabilities," in 2016 International Conference on Universal Access in Human-Computer Interaction (pp. 505-515). Springer, Cham.

Ferreira, J.M., Acuna, S.T., Dieste, O., Vegas, S., Santos, A., Rodriguez, F. and Juristo, N., 2020. "Impact of usability mechanisms: An experiment on efficiency, effectiveness and user satisfaction," in Information and Software Technology, 117, p.106195.

Ghidini. E, Almeida.W, Manssour. I, and Silveira. M. 2016. "Developing Apps for Visually Impaired People: Lessons Learned from Practice," in 2016 49th Hawaii International Conference on System Sciences (HICSS), Koloa, HI, USA, pp. 5691-5700, doi: 10.1109/HICSS.2016.704.

Gintner. V, Balata. J, Boksansky. J and Mikovec. Z. 2017. "Improving reverse geocoding: Localization of blind pedestrians using conversational UI," in 2017 8th IEEE International Conference on Cognitive Infocommunications (CogInfoCom), Debrecen, 2017, pp. 000145000150, doi: 10.1109/CogInfoCom. 8268232.

Gokhale. P, Pimpalkar. N, Sawke. N , and Swain. D. 2017. "SparshJa: A User-Centric Mobile Application Designed for Visually Impaired," in Computational Intelligence in Data Mining, vol. 556, H. S. Behera and D. P. Mohapatra, Eds. Singapore: Springer Singapore, pp. 405-414.

Griffin-Shirley, Nora \& Banda, Devender \& Ajuwon, Paul \& Cheon, Jongpil \& Lee, Jaehoon \& Park, Hye \& Lyngdoh, Sanpalei. 2017. "A Survey on the Use of Mobile Applications for People who Are Visually Impaired," in Journal of visual impairment \& blindness. 111. 307-323. 10.1177/0145482X1711100402.

Grussenmeyer. W, \& Folmer. E. 2017. "Accessible touchscreen technology for people with visual impairments: a survey," in ACM Transactions on Accessible Computing (TACCESS), $9(2), 1-31$.

Hossain. M, Qaiduzzaman. K, and Rahman. M. 2020. "Sightless Helper: An Interactive Mobile Application for Blind Assistance and Safe Navigation," in International Conference on Cyber Security and Computer Science, pp. 581-592.

Peer) Comput. Sci. reviewing PDF | (CS-2021:07:63198:2:0:CHECK 9 Oct 2021) 
930 Juneja. P and Kaur. P. 2019. "Software Engineering for Big Data Application Development:

931 Systematic Literature Survey Using Snowballing," in 2019 International Conference on

932 Computing, Power and Communication Technologies (GUCON), NCR New Delhi, India, pp.

$933 \quad 492-496$.

934

935 Kameswaran. V, Fiannaca. A, Kneisel. M, Karlson. A, Cutrell. E, and Ringel Morris. M. 2020.

936 "Understanding In-Situ Use of Commonly Available Navigation Technologies by People with

937 Visual Impairments," in the 22nd International ACM SIGACCESS Conference on Computers

938 and Accessibility, pp. 1-12.

939

940 Keele. S .2007. "Guidelines for performing systematic literature reviews in software

941 engineering," in Technical report, EBSE Technical Report EBSE-2007-01.

942

943 Khan. A, \& Khusro. S. 2019. "Blind-friendly user interfaces-a pilot study on improving the

944 accessibility of touchscreen interfaces," in Multimedia Tools and Applications, 78(13), 17495-

94517519.

946

947

Khan. A, Khusro. S, and Alam. I. 2018. "Blindsense: An accessibility-inclusive universal user

948 interface for blind people," in Eng. Technol. Appl. Sci. Res., vol. 8, no. 2, pp. 2775-2784.

949

950

Khan. A, Khusro. S. 2020. "An insight into smartphone-based assistive solutions for visually

951 impaired and blind people: issues, challenges and opportunities," in Univ Access Inf Soc (2020).

952 https://doi.org/10.1007/s10209-020-00733-8

953

954

Khowaja. K, Al-Thani. D, Aqle. A, and Banire. B. 2019. "Accessibility or Usability of the User

955 Interfaces for Visually Impaired Users? A Comparative Study," in Lecture Notes in Computer

956 Science (including subseries Lecture Notes in Artificial Intelligence and Lecture Notes in

957 Bioinformatics), vol. 11572 LNCS. pp. 268-283, doi: 10.1007/978-3-030-23560-4_20.

958

959

Khusro. S, Niazi. B, Khan. A, \& Alam, I. 2019. "Evaluating Smartphone Screen Divisions for

960 Designing Blind-Friendly Touch-Based Interfaces," in 2019 International Conference on

961 Frontiers of Information Technology (FIT) (pp. 458-3285). IEEE.

962

963 Kim, Hyun. K \& Han, Sung \& Park, Jaehyun \& Park, Joohwan. 2016. "The interaction

964 experiences of visually impaired people with assistive technology: A case study of

965 smartphones," in International Journal of Industrial Ergonomics. 55. 22-33.

966 10.1016/j.ergon.2016.07.002.

967 
968 Knutas. A, Hajikhani. A, Salminen. J, Ikonen. J, and Porras. J. 2015. "Cloud-based bibliometric 969 analysis service for systematic mapping studies," in International Conference on Computer 970 Systems and Technologies, Dublin.

971

972 Kunaratana-Angkul. Y, Wu. K, and Shin-Renn. Y. 2020. "Usability in the app Interface

973 Designing for the Elderly with Low-Vision in Taiwan and Thailand," in 2020 IEEE 2nd Eurasia

974 Conference on Biomedical Engineering, Healthcare and Sustainability (ECBIOS), Tainan,

975 Taiwan, pp. 64-67, doi: 10.1109/ECBIOS50299.2020.9203640.

976

977

978

979

980

981

982

983

984

985

986

987

988

989

990

991

992

993

994

995

996

997

998

999

1000

1001

1002

1003

1004

1005

1006

Leporini. B, \& Palmucci. E. 2018. “Accessible Question Types on a Touch-Screen Device: The Case of a Mobile Game App for Blind People," in International Conference on Computers Helping People with Special Needs (pp. 262-269). Springer, Cham.

Lewis. P, Ayton. L, Guymer. R, et al. 2016. "Advances in implantable bionic devices for blindness: a review," in ANZ J Surg ;86(9):654-659. doi:10.1111/ans.13616

Liberati. A et al. 2009. "The prisma statement for reporting systematic reviews and metaanalyses of studies that evaluate health care interventions: Explanation and elaboration,"' in PLoS Med, vol. 6, no. 7, Art. no. e1000100.

Long. S, Karpinsky. N, Döner. H, and Still. J. 2016. "Using a mobile application to help visually impaired individuals explore the outdoors," in Advances in design for inclusion, Springer, pp. 213-223.

Madrigal-Cadavid. J, Amariles. P, Pino-Marín. D, Granados. J, and Giraldo. N. 2020. "Design and development of a mobile app of drug information for people with visual impairment," in Res. Soc. Adm. Pharm., vol. 16, no. 1, pp. 62-67, doi: 10.1016/j.sapharm.2019.02.013.

Maly. I, Balata. J, Krejcir. O, Fuzessery. E, and Mikovec. Z. 2015. "Qualitative measures for evaluation of navigation applications for visually impaired," in 2015 6th IEEE International Conference on Cognitive Infocommunications (CogInfoCom), pp. 223-228.

Marques. D, Carriço. L, and Guerreiro. T. 2015. "Assessing Inconspicuous Smartphone Authentication for Blind People," in p. 5.

McKay. M. 2017. "Accessibility Challenges of Hybrid Mobile Applications," in Universal Access in Human-Computer Interaction: Design And Development Approaches and Methods, PT I, vol. 10277, pp. 193-208, doi: 10.1007/978-3-319-58706-6_16. 
1007 Morris. M, Zolyomi. A, Yao. C, Bahram. S, Bigham. J, and Kane. S. 2016. "With most of it 1008 being pictures now, I rarely use it' Understanding Twitter's Evolving Accessibility to Blind 1009 Users," in Proceedings of the 2016 CHI Conference on Human Factors in Computing Systems, 1010 pp. 5506-5516.

1011

1012 Nahar. L, Jaafar. A, and Sulaiman. R. 2019. "Usability Evaluation of a Mobile Phone Based 1013 Braille Learning Application 'MBRAILLE,' in. pp., no. p. 10, 2019.

1014 1015

Nahar. L, Sulaiman. R, and Jaafar. A. 2020. "An interactive math braille learning application to 1017 1018 assist blind students in Bangladesh,” in Assist. Technol., pp. 1-13, Mar. doi: 10.1080/10400435.2020.1734112.

1021

1022

1023

1024

Nair. V, Olmschenk. G, Seiple. W, and Zhu. Z. 2020. "ASSIST: Evaluating the usability and performance of an indoor navigation assistant for blind and visually impaired people," in Assistive Technology, pp. 1-11.

1025

Niazi. B, Khusro. S, Khan. A, \& Alam. I. 2016. "A touch-sensitive keypad layout for improved usability of smartphones for the blind and visually impaired persons," in Artificial Intelligence 1026 Perspectives in Intelligent Systems (pp. 427-436). Springer, Cham.

1028

1029

1030

1031

1032

1033

1034

1035

1036

1037

1038

1039

1040

1041

1042

1043

1044

1045

1046

Oliveira. J, Borges. O, Paix ao-Cortes. V, Campos. M and Damasceno. R. 2018. "L^eR' otulos: A Mobile Application Based on Text Recognition in Images to AssistVisually Impaired People", in 2018 International Conference on Universal Access in Human-Computer Interaction, pp. 337354. Springer, Cham.

Ouzzani. M, Hammady. H, Fedorowicz. Z. et al. 2016. "Rayyan—a web and mobile app for systematic reviews," in Syst Rev 5, 210. https://doi.org/10.1186/s13643-016-0384-4

Paiva. D, da Silva Batista. M, Zaina. L, and de Mattos Fortes. R. 2020. "Acc-MobileCheck: a Checklist for Usability and Accessibility Evaluation of Mobile Applications," in CLEI Electron. J., vol. 23 , no. 2.

Palani. H, Tennison. J, Giudice. G, \& Giudice. N. 2018. “Touchscreen-based haptic information access for assisting blind and visually-impaired users: Perceptual parameters and design guidelines," in International Conference on Applied Human Factors and Ergonomics (pp. 837847). Springer, Cham.

Pereda. K, Murillo. B, and Paz. F. 2020. "Visually Impaired Accessibility Heuristics Proposal for e-Commerce Mobile Applications," in International Conference on Human-Computer Interaction, pp. 240-252.

Peer) Comput. Sci. reviewing PDF | (CS-2021:07:63198:2:0:CHECK 9 Oct 2021) 
1047

1048

1049

1050

1051

1052

1053

1054

1055

1056

1057

1058

1059

1060

1061

1062

1063

1064

1065

1066

1067

1068

1069

1070

1071

1072

1073

1074

1075

1076

1077

1078

1079

1080

1081

1082

1083

1084

1085
Prerana. V, Tejaswini. S, Manandhar. J, Santhosh. T, Pushpa. S, and Manjunath. T. 2019. "STAVI: Smart Travelling Application for the Visually Impaired," in 2019 International Conference on Communication and Electronics Systems (ICCES), pp. 1427-1432.

Qureshi. H and Wong. D. 2020. "Usability of user-centric mobile application design from visually impaired people's perspective," in Lecture Notes in Computer Science (including subseries Lecture Notes in Artificial Intelligence and Lecture Notes in Bioinformatics), vol. 12188 LNCS. pp. 311-322, doi: 10.1007/978-3-030-49282-3_22.

Rahman. A, Anam. A.I. \& Yeasin. M. 2017. "E m o A s i s t: emotion enabled assistive tool to enhance dyadic conversation for the blind," in Multimed Tools Appl 76, 7699-7730.

https://doi.org/10.1007/s11042-016-3295-4

Rodrigues. A, Montague. K, Nicolau. H and Guerreir. T. 2015. "Getting Smartphones to Talkback: Understanding the Smartphone Adoption Process of Blind Users," in 2015 Proceedings of the 17th International ACM SIGACCESS Conference on Computers \& Accessibility, pp. 23-32.

Rosner. Y, Perlman. A. 2018. "The Effect of the Usage of Computer-Based Assistive Devices on the Functioning and Quality of Life of Individuals who are Blind or have low Vision," in Journal of Visual Impairment \& Blindness ;112(1):87-99. doi:10.1177/0145482X1811200108

Sabab. S and Ashmafee. M. 2016. "Blind Reader: An intelligent assistant for blind," in 2016 19th International Conference on Computer and Information Technology (ICCIT), Dhaka, pp. 229234, doi: 10.1109/ICCITECHN.7860200.

Skulimowski. P, Owczarek. M, Radecki. A et al. 2019. "Interactive sonification of U-depth images in a navigation aid for the visually impaired," in J Multimodal User Interfaces 13, 219230. https://doi.org/10.1007/s12193-018-0281-3

Smaradottir. B, Martinez. S and Håland. J. 2017. "Evaluation of touchscreen assistive technology for visually disabled users," in 2017 IEEE Symposium on Computers and Communications (ISCC), Heraklion, pp. 248-253, doi: 10.1109/ISCC.2017.8024537.

Smaradottir. B, Martinez. S, and Haland. J. 2017. "Evaluation of touchscreen assistive technology for visually disabled users," in 2017 IEEE Symposium on Computers and Communications (ISCC).

Peer] Comput. Sci. reviewing PDF | (CS-2021:07:63198:2:0:CHECK 9 Oct 2021) 
1086 Sonth. S and Kallimani. J. 2017. "OCR based facilitator for the visually challenged," in 2017

1087 International Conference on Electrical, Electronics, Communication, Computer, and

1088 Optimization Techniques (ICEECCOT), Mysuru, pp. 1-7, doi:

1089 10.1109/ICEECCOT.2017.8284628.

1090

1091 Tanfield. D, Denyer. D, Smart. P.2003. "Towards a methodology for developing evidence-

1092 informed management knowledge by means of systematic review," in Br. J. Manag. 14 (3), $207-$

1093222.

1094

1095

Vashistha. A, Cutrell. E, Dell. N, and Anderson. R. 2015. "Social Media Platforms for Low-

1096

Income Blind People in India," in Proceedings of the 17th International ACM SIGACCESS

1097

Conference on Computers \& Accessibility (ASSETS '15). Association for Computing

1098

1099

1100

Machinery, New York, NY, USA, 259-272. DOI:https://doi.org/10.1145/2700648.2809858

1101

Vitiello. G, et al. 2018. "Do you like my outfit?: Cromnia, a mobile assistant for blind users," in

1102

Proceedings of the 4th EAI International Conference on Smart Objects and Technologies for

1103

1104

Social Good - Goodtechs '18, Bologna, Italy, pp. 249-254, doi: 10.1145/3284869.3284908.

1105

W. Health Organization, Ed., "Global data on visual impairment," [Online]. Available:

https://www.who.int/blindness/publications/globaldata/en/ [Accessed: 02-Dec-2020].

1106

1107

1108

1109

Zhang. H, Babar. M, and Tell. P. 2011. "Identifying relevant studies in software engine".

1110

Zhou. Y, Zhang. H, Huang. X, Yang. S, Babar. M, and Tang. H. 2015. "Quality assessment of systematic reviews in software engineering: a tertiary study," in Proceedings of the 19th

1111

International Conference on Evaluation and Assessment in Software Engineering (EASE '15).

1112

Association for Computing Machinery, New York, NY, USA, Article 14, 1-14.

1113

1114

\section{Appendix}

1115 References selected for each theme

1116

1117 


\section{Table $\mathbf{1}$ (on next page)}

Research questions 


\begin{tabular}{|c|c|}
\hline Research Question & Description and Motivation \\
\hline $\begin{array}{l}\text { RQ1: What existing UVI issues did authors } \\
\text { try to solve with mobile devices? }\end{array}$ & $\begin{array}{l}\text { The issues and proposed solutions will be of } \\
\text { great significance for researchers as well as } \\
\text { developers, providing a deeper understanding } \\
\text { of whether a specific problem was addressed in } \\
\text { the literature and what the proposed solutions } \\
\text { were. }\end{array}$ \\
\hline $\begin{array}{l}\text { RQ2: What is the role of mobile devices in } \\
\text { solving those issues? }\end{array}$ & $\begin{array}{l}\text { Being able to identify the role of mobile devices } \\
\text { in assisting visually impaired people in their } \\
\text { daily lives will help improve their usability and } \\
\text { provide a basis for future applications to be } \\
\text { developed to improve quality of life for the } \\
\text { visually impaired. }\end{array}$ \\
\hline $\begin{array}{l}\text { RQ3: What are the publication trends on } \\
\text { the usability of mobile applications among } \\
\text { the visually impaired? }\end{array}$ & $\begin{array}{l}\text { After answering this question, it will become } \\
\text { easier to classify the current existing work and } \\
\text { the available application themes for the visually } \\
\text { impaired. }\end{array}$ \\
\hline $\begin{array}{l}\text { RQ4: What are the current research } \\
\text { limitations and future research directions } \\
\text { regarding usability among the visually } \\
\text { impaired? }\end{array}$ & $\begin{array}{l}\text { This will help guide future research and open } \\
\text { doors for new development. }\end{array}$ \\
\hline $\begin{array}{l}\text { RQ5: What is the focus of research on } \\
\text { usability for visually impaired people, and } \\
\text { what are the research outcomes in the } \\
\text { studies reviewed? }\end{array}$ & $\begin{array}{l}\text { Answering this question, will enable us to } \\
\text { address the current focus of studies and the } \\
\text { available ways to collect data. }\end{array}$ \\
\hline $\begin{array}{l}\text { RQ6: What evaluation methods were used } \\
\text { in the studies on usability for visually } \\
\text { impaired people that were reviewed? }\end{array}$ & $\begin{array}{l}\text { This evaluation will help future researchers } \\
\text { choose the most suitable methods according to } \\
\text { the nature of their studies. }\end{array}$ \\
\hline
\end{tabular}




\section{Table 2 (on next page)}

Theme-based future work 


\begin{tabular}{|c|c|c|}
\hline Theme & Suggestions for Future Work & Sources \\
\hline Accessibility & $\begin{array}{l}\text { In terms of accessibility, in the future, there is potential } \\
\text { in investigating concepts of how information will be } \\
\text { introduced in a mobile application to increase } \\
\text { accessibility VI users. In addition, future work directions } \\
\text { include extending frameworks for visually complex or } \\
\text { navigationally dense applications. Furthermore, } \\
\text { emotion-based UI design may also be investigated to } \\
\text { improve accessibility. Moreover, the optimization of } \\
\text { GUI layouts and elements could be considered with a } \\
\text { particular focus on gesture control systems and eye- } \\
\text { tracking systems. }\end{array}$ & $\begin{array}{l}\text { (Darvishy, } \\
\text { Hutter \& Frei, } \\
\text { 2019), (Khan, } \\
\text { Khusro \& Alam, } \\
\text { 2018), (Paiva et } \\
\text { al., 2020), } \\
\text { (Khowaja et al., } \\
\text { 2019), and } \\
\text { (Carvalho et al., } \\
\text { 2018) }\end{array}$ \\
\hline $\begin{array}{l}\text { Assistive } \\
\text { Devices }\end{array}$ & $\begin{array}{l}\text { In terms of assistive devices for people with visual } \\
\text { impairments, there is potential for future direction in } \\
\text { research into multimodal non-visual interaction (e.g., } \\
\text { sonification methods). Also, since there is very little } \\
\text { available literature about how to go about prototype } \\
\text { development and evaluation activities for assistive } \\
\text { devices for users with no or little sight, it is important to } \\
\text { investigate this to further develop the field. }\end{array}$ & $\begin{array}{l}\text { (Skulimowski et } \\
\text { al.,2019), } \\
\text { (Bharatia, } \\
\text { Ambawane \& } \\
\text { Rane, 2019), } \\
\text { (Csapó et al., } \\
\text { 2015), and } \\
\text { (Rahman et al., } \\
\text { 2017) }\end{array}$ \\
\hline $\begin{array}{l}\text { Daily } \\
\text { Activities }\end{array}$ & $\begin{array}{l}\text { There is a need to evaluate the usability and accessibility } \\
\text { of applications that aim to assist visually impaired users } \\
\text { and improve restrictions in daily activities. }\end{array}$ & $\begin{array}{l}\text { (Madrigal- } \\
\text { Cadavid et al., } \\
\text { 2019) } \\
\text {,(Oliveira et al., } \\
\text { 2018), and } \\
\text { (Rodrigues et } \\
\text { al., 2015) }\end{array}$ \\
\hline $\begin{array}{l}\text { Screen } \\
\text { Division } \\
\text { Layout }\end{array}$ & $\begin{array}{l}\text { In terms of screen division layout, it is important to } \\
\text { continuously seek to improve interfaces and provide } \\
\text { feedback to make them more focused, more cohesive, } \\
\text { and simpler to handle. A complete set of robust design } \\
\text { guidelines ought to be created to provide a wide variety } \\
\text { of non-visual applications with increased haptic access } \\
\text { on a touchscreen device. }\end{array}$ & $\begin{array}{l}\text { (Khusro et al., } \\
\text { 2019), (Alnfiai } \\
\text { \& Sampalli, } \\
\text { 2019), (Palani } \\
\text { et al., 2018), } \\
\text { and (Khan, \& } \\
\text { Khusro, 2019) }\end{array}$ \\
\hline Gestures & $\begin{array}{l}\text { Gesture based interaction ought to be further } \\
\text { investigated as it has the potential to greatly improve the } \\
\text { way VI users communicate with mobile devices. } \\
\text { Performance of gestures with various sizes of touch } \\
\text { screens ought to be compared, as the size might have a } \\
\text { significant effect on what is considered a usable gesture. }\end{array}$ & $\begin{array}{l}\text { (Alnfiai \& } \\
\text { Sampalli, 2017) } \\
\text { and (Buzzi et } \\
\text { al., 2017) }\end{array}$ \\
\hline Navigation & Literature suggests that future work in the area of & \\
\hline
\end{tabular}




\begin{tabular}{|c|c|c|}
\hline & $\begin{array}{l}\text { navigation should focus on eliminating busy graphical } \\
\text { interfaces and relying on sounds. Studying more } \\
\text { methods and integrating machine learning algorithms } \\
\text { and hardware devices to provide accurate results } \\
\text { regarding the identification of surrounding objects, and } \\
\text { continuous updates for any upcoming obstacles, is also } \\
\text { discussed in the literature as an important direction for } \\
\text { future work. }\end{array}$ & $\begin{array}{l}\text { (Darvishy et al., } \\
\text { 2020), (Hossain, } \\
\text { Qaiduzzaman \& } \\
\text { Rahman, 2020), } \\
\text { (Hossain, } \\
\text { Qaiduzzaman \& } \\
\text { Rahman, 2020), } \\
\text { and (Bandukda } \\
\text { et al., 2020) }\end{array}$ \\
\hline $\begin{array}{l}\text { Audio } \\
\text { Guidance }\end{array}$ & $\begin{array}{l}\text { In terms of audio guidance, there is potential for future } \\
\text { directions in expanding algorithms to provide audio } \\
\text { guidance to assist in more situations. Authors also } \\
\text { emphasise developing versions of the applications in } \\
\text { more languages. }\end{array}$ & $\begin{array}{l}\text { (Gintner et al., } \\
\text { 2017), (Sabab \& } \\
\text { Ashmafee, } \\
\text { 2016) and } \\
\text { (Façanha et al., } \\
\text { 2016) }\end{array}$ \\
\hline
\end{tabular}




\section{Table 3(on next page)}

\section{Appendix 1}


Appendix

References selected for each theme

\begin{tabular}{|c|c|c|}
\hline No. & Name of the study & Category \\
\hline 1. & $\begin{array}{l}\text { Making mobile map applications accessible for } \\
\text { visually impaired people }\end{array}$ & Accessibility \\
\hline 2. & $\begin{array}{l}\text { With most of it being pictures now, I rarely use it' } \\
\text { Understanding Twitter's Evolving Accessibility to } \\
\text { Blind Users. }\end{array}$ & Accessibility \\
\hline 3. & $\begin{array}{l}\text { Usability of user-centric mobile application design } \\
\text { from visually impaired people's perspective. }\end{array}$ & Accessibility \\
\hline 4. & $\begin{array}{l}\text { Blindsense: An accessibility-inclusive universal user } \\
\text { interface for blind people. }\end{array}$ & Accessibility \\
\hline 5. & $\begin{array}{l}\text { Acc-MobileCheck: a Checklist for Usability and } \\
\text { Accessibility Evaluation of Mobile Applications. }\end{array}$ & Accessibility \\
\hline 6. & $\begin{array}{l}\text { Visually Impaired Accessibility Heuristics Proposal } \\
\text { for e-Commerce Mobile Applications. }\end{array}$ & Accessibility \\
\hline 7. & $\begin{array}{l}\text { Accessibility or Usability of the User Interfaces for } \\
\text { Visually Impaired Users? A Comparative Study. }\end{array}$ & Accessibility \\
\hline 8. & $\begin{array}{l}\text { Accessibility and Usability Problems Encountered on } \\
\text { Websites and Applications in Mobile Devices by } \\
\text { Blind and Normal-Vision Users. }\end{array}$ & Accessibility \\
\hline 9. & $\begin{array}{l}\text { Preliminary Evaluation of Interactive Search Engine } \\
\text { Interface for Visually Impaired Users. }\end{array}$ & Accessibility \\
\hline 10. & $\begin{array}{l}\text { Accessibility Challenges of Hybrid Mobile } \\
\text { Applications. }\end{array}$ & Accessibility \\
\hline 11. & $\begin{array}{l}\text { Evaluation of touchscreen assistive technology for } \\
\text { visually disabled users. }\end{array}$ & Assistive Devices \\
\hline 12. & $\begin{array}{l}\text { Interactive sonification of U-depth images in a } \\
\text { navigation aid for the visually impaired. }\end{array}$ & Assistive Devices \\
\hline 13. & $\begin{array}{l}\text { UniPass: design and evaluation of a smart device- } \\
\text { based password manager for visually impaired users. }\end{array}$ & Assistive Devices \\
\hline 14. & $\begin{array}{l}\text { The Effect of the Usage of Computer-Based Assistive } \\
\text { Devices on the Functioning and Quality of Life of } \\
\text { Individuals who are Blind or have low Vision. }\end{array}$ & Assistive Devices \\
\hline 15. & $\begin{array}{l}\text { A survey of assistive technologies and applications for } \\
\text { blind users on mobile platforms: a review and } \\
\text { foundation for research. }\end{array}$ & Assistive Devices \\
\hline 16. & $\begin{array}{l}\text { An insight into smartphone-based assistive solutions } \\
\text { for visually impaired and blind people: issues, } \\
\text { challenges and opportunities. }\end{array}$ & Assistive Devices \\
\hline 17. & OCR based facilitator for the visually challenged. & Assistive Devices \\
\hline 18. & $\begin{array}{l}\text { The interaction experiences of visually impaired } \\
\text { people with assistive technology: A case study of } \\
\text { smartphones. }\end{array}$ & Assistive Devices \\
\hline
\end{tabular}




\begin{tabular}{|c|c|c|}
\hline 19. & $\begin{array}{l}\text { Social Media Platforms for Low-Income Blind People } \\
\text { in India. }\end{array}$ & Assistive Devices \\
\hline 20. & $\begin{array}{l}\text { Understanding In-Situ Use of Commonly Available } \\
\text { Navigation Technologies by People with Visual } \\
\text { Impairments. }\end{array}$ & Assistive Devices \\
\hline 21. & $\begin{array}{l}\text { A Survey on the Use of Mobile Applications for } \\
\text { People who Are Visually Impaired. }\end{array}$ & Assistive Devices \\
\hline 22. & $\begin{array}{l}\text { Smart Electronic Stick for Visually Impaired using } \\
\text { Android Application and Google's Cloud Vision. }\end{array}$ & Assistive Devices \\
\hline 23. & $\begin{array}{l}\text { Advances in implantable bionic devices for blindness: } \\
\text { a review. }\end{array}$ & Assistive Devices \\
\hline 24. & $\begin{array}{l}\text { An interactive math braille learning application to } \\
\text { assist blind students in Bangladesh. }\end{array}$ & Daily Activities \\
\hline 25. & $\begin{array}{l}\text { Usability evaluation of a mobile phone-based braille } \\
\text { learning application 'mbraille. }\end{array}$ & Daily Activities \\
\hline 26. & $\begin{array}{l}\text { Design and usability of a braille-based mobile } \\
\text { audiogame environment. }\end{array}$ & Daily Activities \\
\hline 27. & $\begin{array}{l}\text { SparshJa: A User-Centric Mobile Application } \\
\text { Designed for Visually Impaired. }\end{array}$ & Daily Activities \\
\hline
\end{tabular}

28. Do you like my outfit?: Cromnia, a mobile assistant for blind users.

29. Usability in the app Interface Designing for the Daily Activities Elderly with Low-Vision in Taiwan and Thailand.

30. Developing Apps for Visually Impaired People: $\quad$ Daily Activities Lessons Learned from Practice.

31. Design and development of a mobile app of drug Daily Activities information for people with visual impairment.

32. Assessing Inconspicuous Smartphone Authentication Daily Activities for Blind People.

33. L`eR'otulos: A Mobile Application Based on Text Daily Activities Recognition in Images to Assist Visually Impaired People.

34. Getting Smartphones to Talkback: Understanding the Daily Activities Smartphone Adoption Process of Blind Users.

35. Evaluating Smartphone Screen Divisions for Designing Blind-Friendly Touch-Based Interfaces.

36. Blind-friendly user interfaces-a pilot study on improving the accessibility of touchscreen interfaces.

37. Accessible touchscreen technology for people with visual impairments: a survey.

38. Touchscreen-based haptic information access for $\quad$ Screen Division Layout assisting blind and visually-impaired users: Perceptual parameters and design guidelines.

39. Accessible Question Types on a Touch-Screen Device: The Case of a Mobile Game App for Blind People. 
40. Touchscreen Based Text-Entry for Visually-Impaired Users.

41. An evaluation of SingleTapBraille keyboard: a text entry method that utilizes braille patterns on touchscreen devices.

42. A touch-sensitive keypad layout for improved usability of smartphones for the blind and visually impaired persons.

43. BraillePassword: accessible web authentication technique on touchscreen devices.

44. An evaluation of the brailleenter keyboard: An input method based on braille patterns for touchscreen devices.

45. Analyzing visually impaired people's touch gestures on smartphones.

46. Evaluation of touchscreen assistive technology for visually disabled users.

47. Improving reverse geocoding: Localization of blind pedestrians using conversational UI.

48. Mobile Audio Games Accessibility Evaluation for Users Who Are Blind.

49. Blind Reader: An intelligent assistant for blind.

50. Audio Description of Videos for People with Visual Disabilities.

51. Ebsar: Indoor guidance for the visually impaired," Computers \& Electrical Engineering.

52. ASSIST: Evaluating the usability and performance of an indoor navigation assistant for blind and visually impaired people.

53. Usability evaluation of a mobile navigation application for blind users.

54. Touch Explorer: Exploring Digital Maps for Visually Impaired People.

55. Emotion enabled assistive tool to enhance dyadic conversation for the blind

56. Sightless Helper: An Interactive Mobile Application for Blind Assistance and Safe Navigation.

57. Using a mobile application to help visually impaired individuals explore the outdoors.

58. STAVI: Smart Travelling Application for the Visually Impaired.

59. PLACES: A Framework for Supporting Blind and Partially Sighted People in Outdoor Leisure Activities.

60. Qualitative measures for evaluation of navigation applications for visually impaired.
Screen Division Layout

Screen Division Layout

Screen Division Layout

Screen Division Layout

Gestures

Gestures

Gestures

Audio Guidance

Audio Guidance

Audio Guidance

Audio Guidance

Navigation

Navigation

Navigation

Navigation

Navigation

Navigation

Navigation

Navigation

Navigation

Navigation 


\section{Figure 1}

\section{Percentages of classification themes}

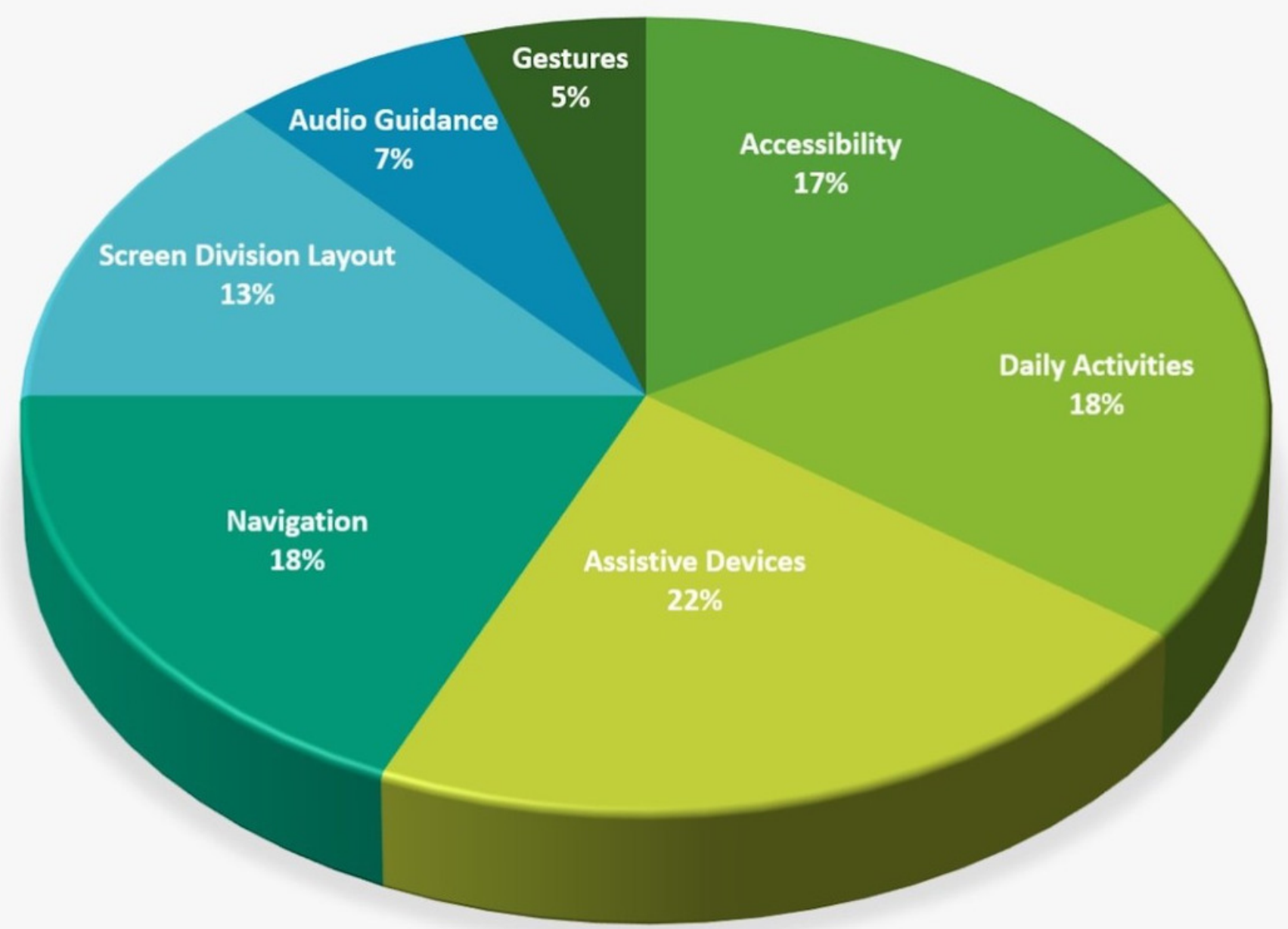


Figure 2

NAILS output sample

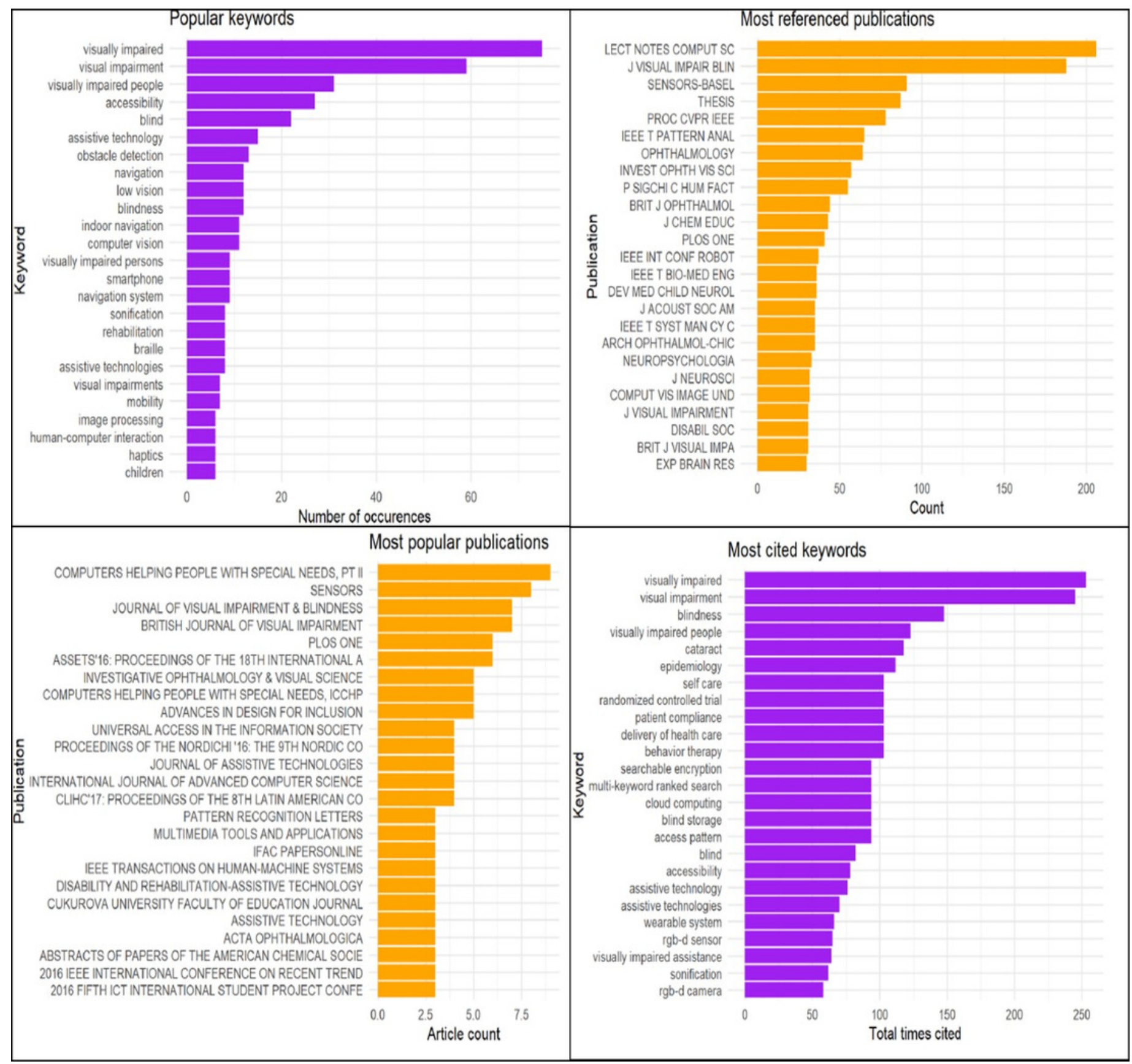




\section{Figure 3}

Number of papers per database

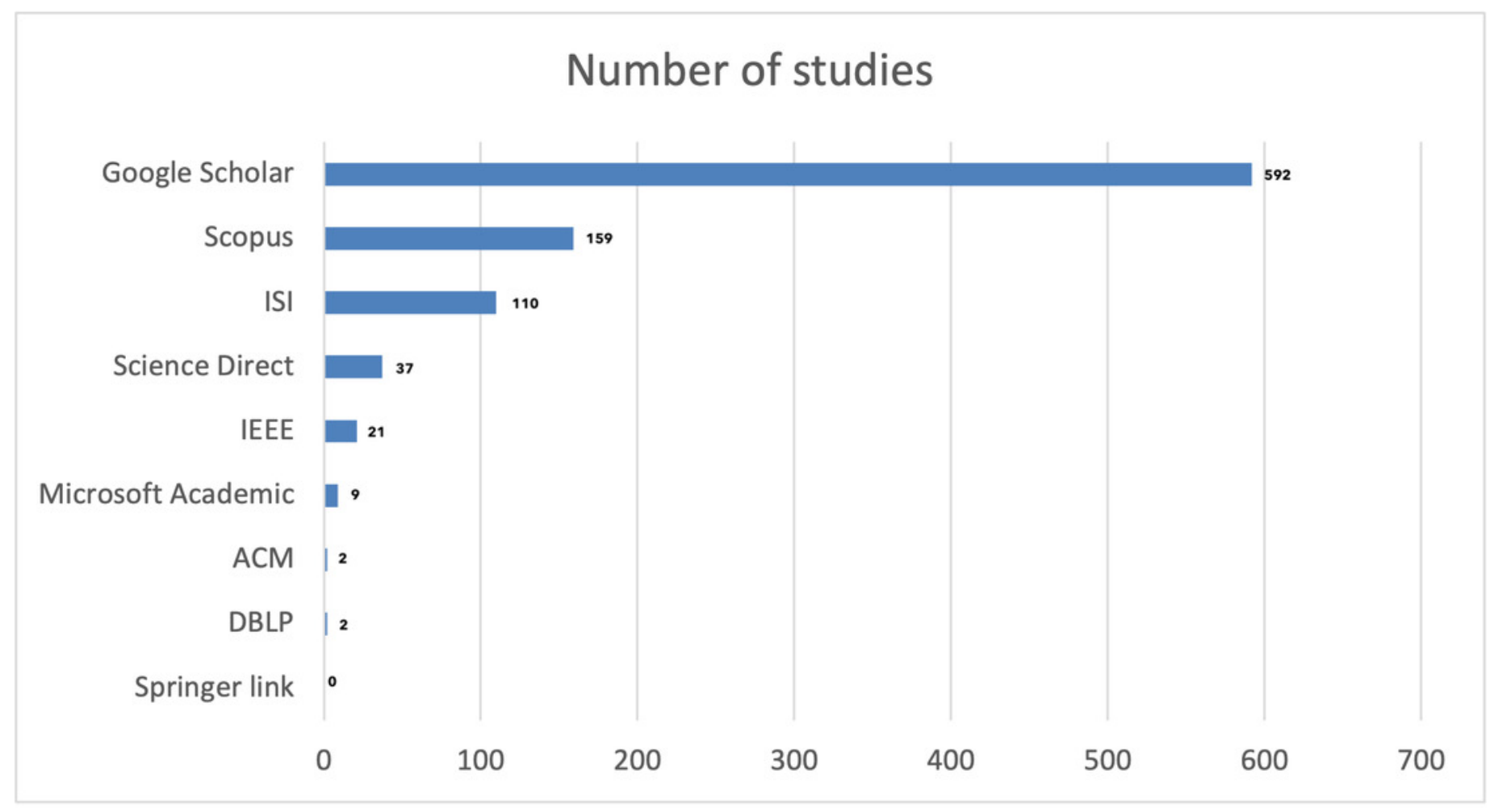


Figure 4

Search stages

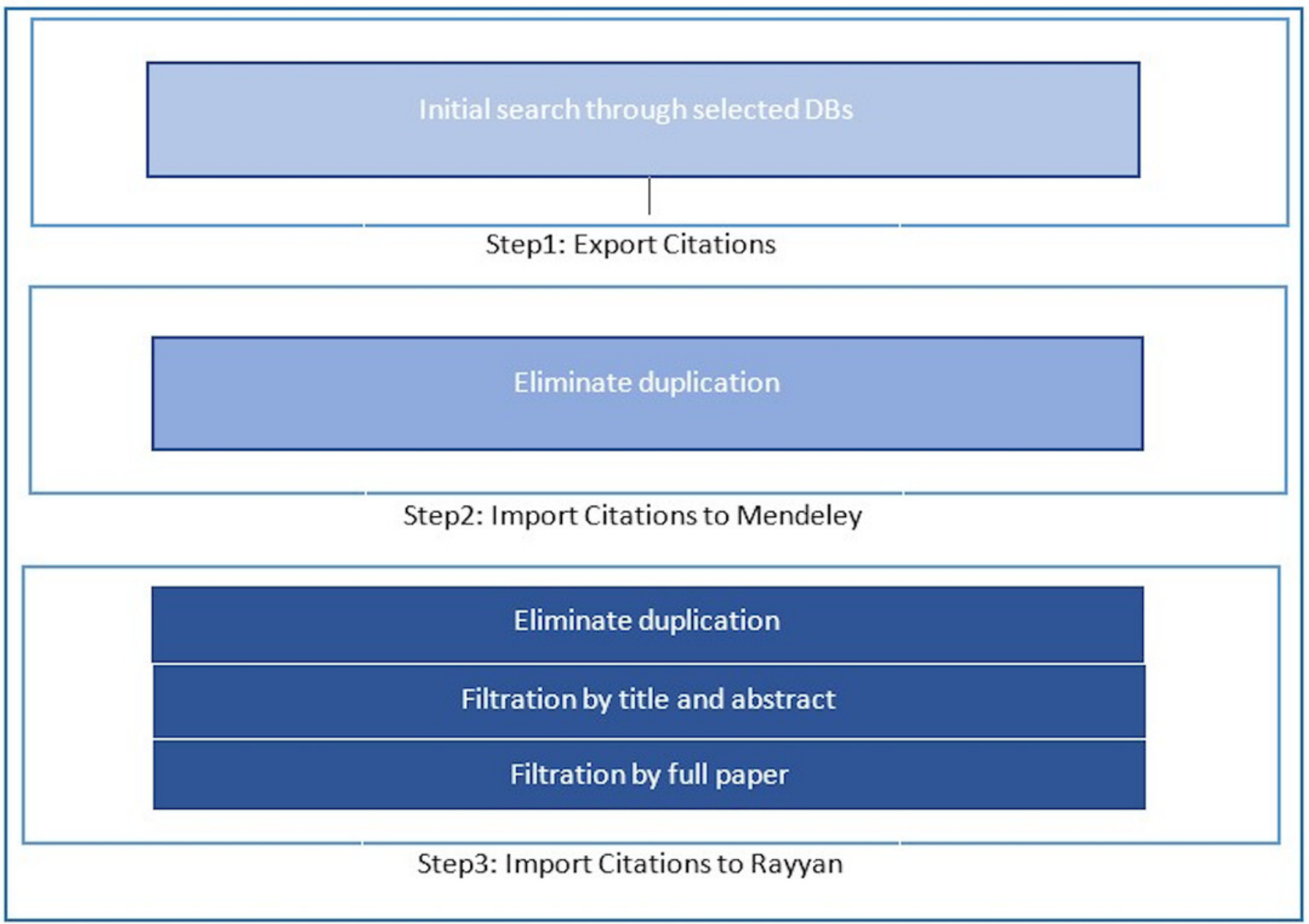


Figure 5

Quality assessment process 


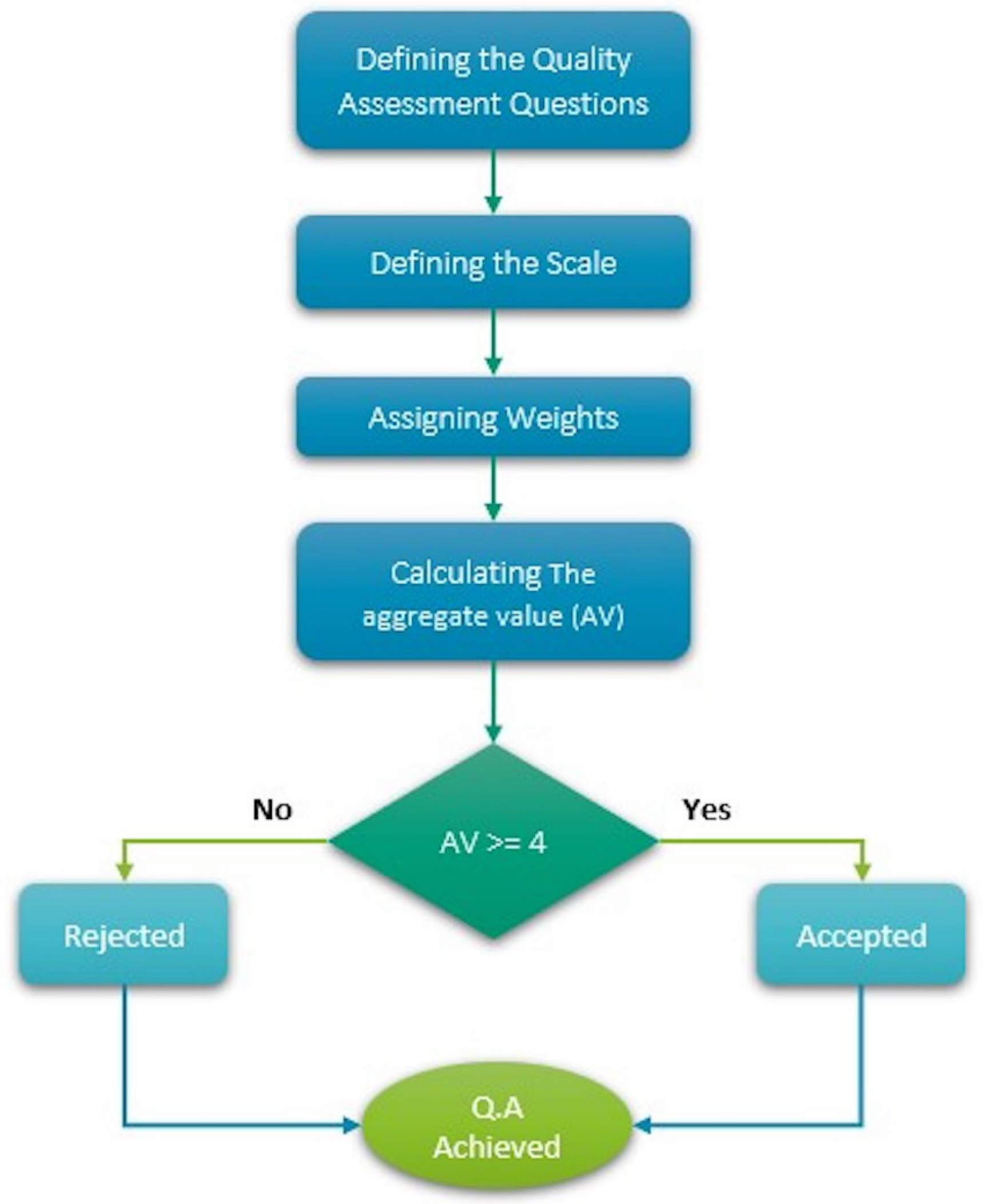


Figure 6

\section{PRISMA flow diagram}
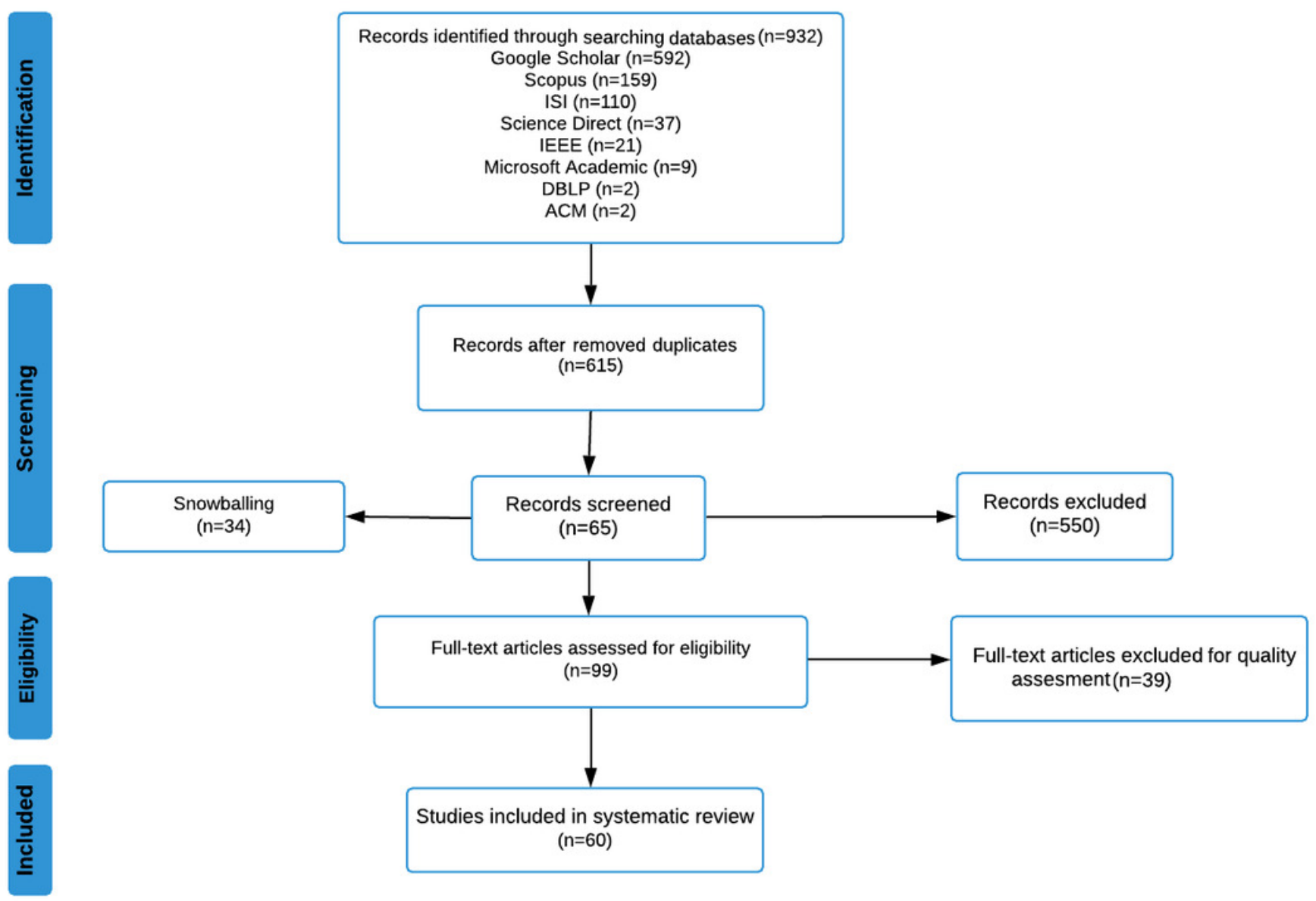


\section{Figure 7}

\section{Results of the SLR}

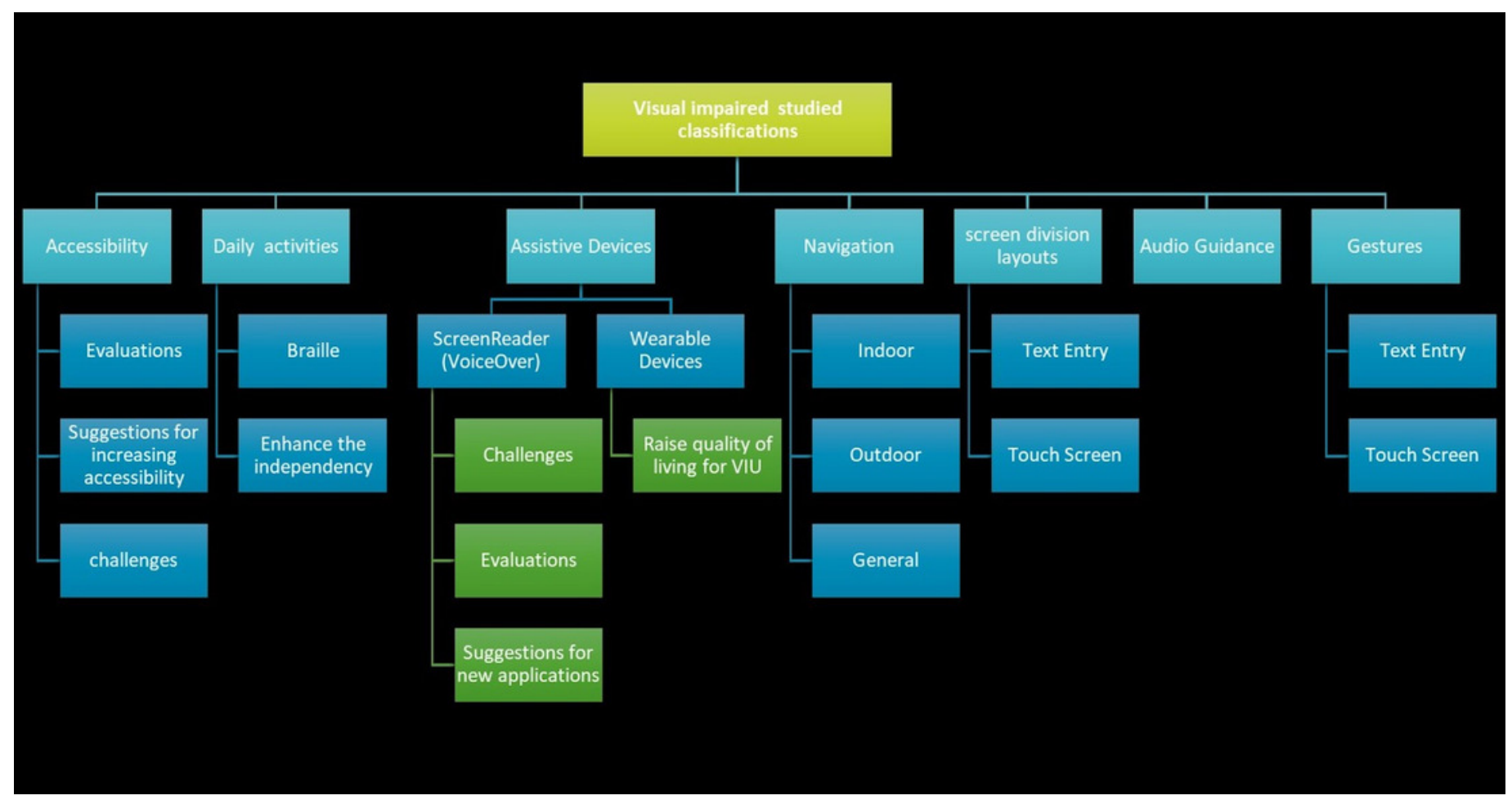


Figure 8

Publication trends over time

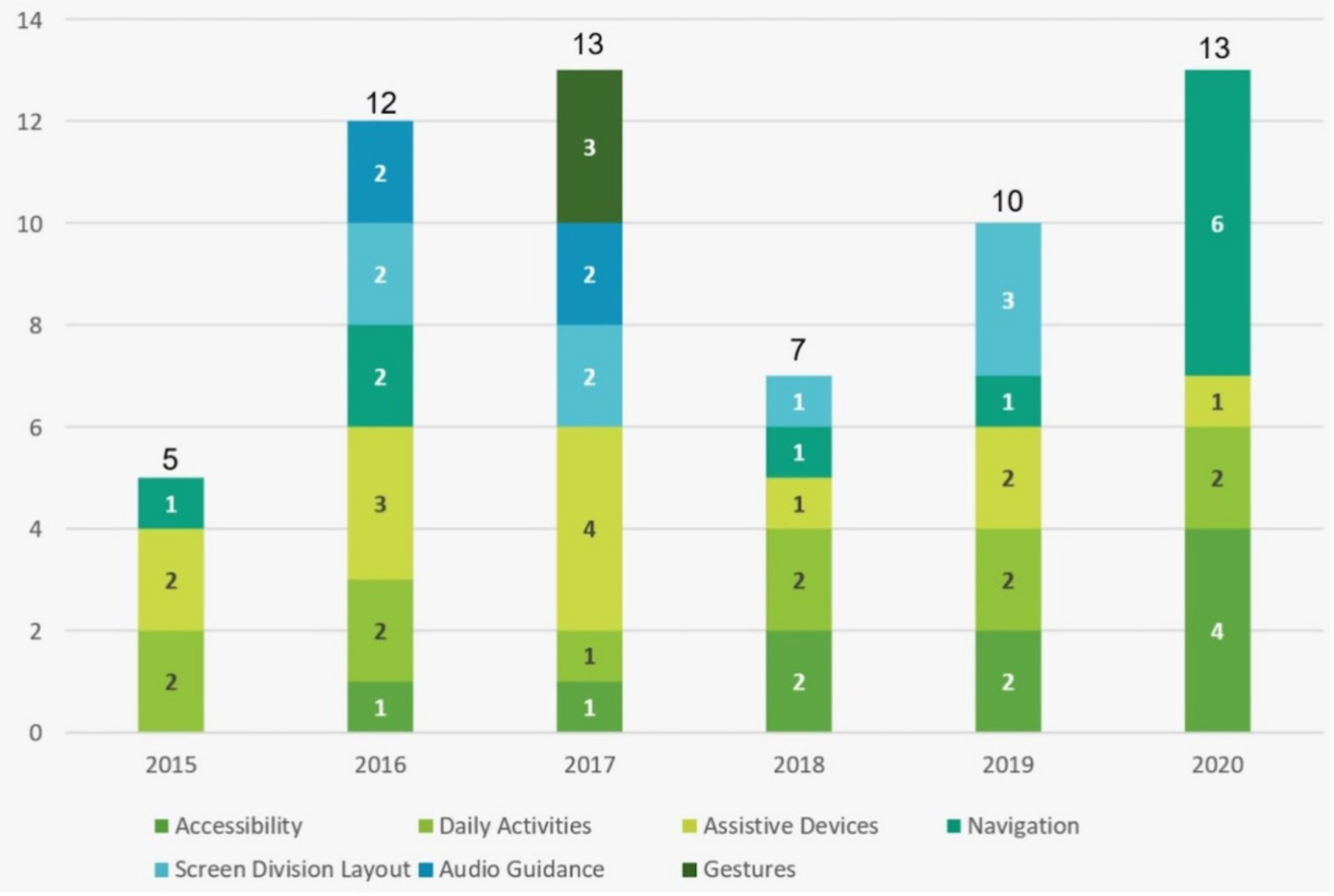


Figure 9

\section{Outcomes of studies}

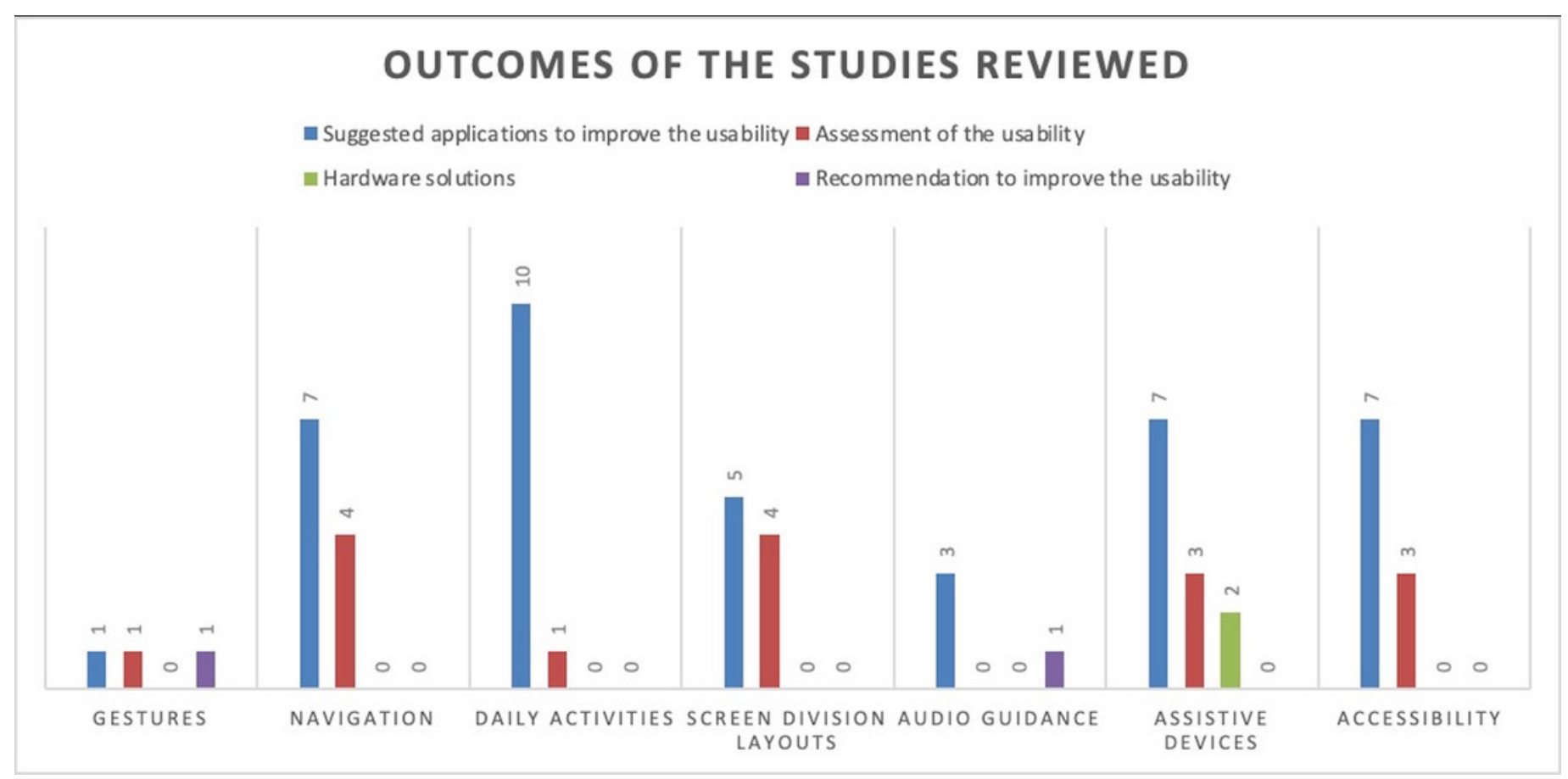

